\title{
Fiber-Optic Microstructure Sensors: A Review
}

\author{
Zengling RAN ${ }^{1 \dagger^{*}}$, Xiu $\mathrm{HE}^{1 \dagger}$, Yunjiang $\mathrm{RAO}^{1^{*}}$, Dong $\mathrm{SUN}^{1}$, Xiaojuan $\mathrm{QIN}^{1}$, \\ Debiao $\mathrm{ZENG}^{2}$, Wangwei $\mathrm{CHU}^{2}$, Xiankun $\mathrm{LI}^{2}$, and Yabin $\mathrm{WEI}^{2}$ \\ ${ }^{1}$ Fiber Optics Research Center (FORC), Key Laboratory of Optical Fiber Sensing \& Communications, University of \\ Electronic Science and Technology of China, Chengdu 611731, China \\ ${ }^{2}$ Chengdu Aircraft Industrial Group Co., Ltd., Chengdu 610092, China \\ ${ }^{\dagger}$ These authors contributed equally to this work \\ *Corresponding authors: Zengling RAN and Yunjiang RAO_ E-mail: ranzl@uestc.edu.cn and yjrao@uestc.edu.cn
}

\begin{abstract}
This paper reviews a wide variety of fiber-optic microstructure (FOM) sensors, such as fiber Bragg grating (FBG) sensors, long-period fiber grating (LPFG) sensors, Fabry-Perot interferometer (FPI) sensors, Mach-Zehnder interferometer (MZI) sensors, Michelson interferometer (MI) sensors, and Sagnac interferometer (SI) sensors. Each FOM sensor has been introduced in the terms of structure types, fabrication methods, and their sensing applications. In addition, the sensing characteristics of different structures under the same type of FOM sensor are compared, and the sensing characteristics of the all FOM sensors, including advantages, disadvantages, and main sensing parameters, are summarized. We also discuss the future development of FOM sensors.
\end{abstract}

Keywords: Fiber-optic sensors; Fabry-Perot, fiber Bragg grating; long period grating; Mach-Zehnder interferometer; Michelson interferometer; Sagnac interferometer

Citation: Zengling RAN, Xiu HE, Yunjiang RAO, Dong SUN, Xiaojuan QIN, Debiao ZENG, et al., "Fiber-Optic Microstructure Sensors: A Review," Photonic Sensors, 2021, 11(2): 227-261.

\section{Introduction}

Fiber-optic sensors have attracted a great deal of interest in the field of telecommunication and sensing due to their inherent advantages of small size, immunity to electromagnetic interference, ability to work in harsh environments, and so on. Among manifold fiber-optic sensors, the fiber-optic microstructure (FOM) sensor, formed by introducing microstructure into optical fiber, is one of the most important devices since it offers unique characteristics of high sensitivity, high resolution, and excellent distributing and multiplexing capabilities. To date, the FOM sensors mainly include fiber Bragg grating (FBG) sensors [1, 2], long-period fiber grating (LPFG) sensors [3, 4], Fabry-Perot interferometer (FPI) sensors [5, 6], Mach-Zehnder interferometer (MZI) sensors [7, 8], Michelson interferometer (MI) sensors [9, 10], and Sagnac interferometer (SI) sensors [11, 12]. Each FOM sensor possesses abundant structures and its fabrication technologies are also various, including chemical etching [13], excimer laser micromachining [14], femtosecond laser micromachining [15], $\mathrm{CO}_{2}$ laser micromachining [16], focused ion beams (FIB) milling[17], and kinds of coating technologies, just to name a few. In addition, these FOM sensors have been widely

Received: 15 March 2021 / Revised: 25 March 2021

(C) The Author(s) 2021. This article is published with open access at Springerlink.com

DOI: $10.1007 / \mathrm{s} 13320-021-0632-7$

Article type: Review 
applied for sensing applications, such as temperature, strain, pressure, force, vibration, displacement, refractive index (RI), and ultrasound. Furthermore, some FOM sensors have been successfully commercialized and widely used for health and safety monitoring of composite materials, large civil engineering structures (e.g., bridges and dams), and quantitative chemical process, etc.

In this paper, we aim to offer a summary of the common FOM sensors, including FBG, LPFG, FPI, MZI, MI, and SI sensors, in terms of structure types, fabrication methods, and sensing applications. Moreover, the sensing characteristics of different structures sensors under the same type of FOM sensor are compared, and the sensing characteristics of the all FOM sensors, including advantage, disadvantages, and main sensing parameters, are summarized. The future development of the FOM sensors is also discussed. It is likely that this review of FOM sensors is helpful for readers' understanding of their state of the art and applications.

\section{Fiber grating sensors}

Fiber grating is a typical optical passive device, which can be formed by periodically changing the RI of the fiber core and cladding. The inscription approaches of fiber grating are colorful, for instance, ultraviolet (UV) exposure [18], femtosecond laser pulses [19], $\mathrm{CO}_{2}$ laser pulses [20], and ion implantation [21], arc discharge[4], chemical etching [22], and machine-induced microbend [23]. The performance comparison of these inscription approaches is shown in Table 1. According to the length of grating period, the optical fiber grating sensor is divided into FBG

Table 1 Summary of the normal inscription approaches of the fiber grating.

\begin{tabular}{|c|c|c|}
\hline Inscription approach & Characteristics & Inscribed grating type \\
\hline UV exposure & $\begin{array}{l}\text { + Mass production } \\
\text {-Needing doped and hydrogen load fiber } \\
\text {-Grating formed unstable under high temperature }\end{array}$ & FBG and LPFG \\
\hline Fs laser & $\begin{array}{l}\text { +Applicability to kinds of optical fibers } \\
\text { +Easy to inscript gratings with different structures } \\
\text { +High micromachining precision } \\
\text { +Grating formed with good high temperature stability } \\
\text {-High fabrication cost }\end{array}$ & FBG and LPFG \\
\hline $\mathrm{CO}_{2}$ laser & $\begin{array}{l}\text { +Applicability to kinds of optical fibers } \\
\text { +Easy to inscript gratings with different structures } \\
\text { +Low fabrication cost } \\
\text { + Grating formed with good temperature stability } \\
\text {-Low micromachining precision }\end{array}$ & Only LPFG \\
\hline Ion implantation & $\begin{array}{l}\text { +Applicability to kinds of optical fibers } \\
+ \text { Grating formed with good high temperature stability } \\
\text {-High fabrication cost }\end{array}$ & Only LPFG \\
\hline Arc discharge & $\begin{array}{l}\text { +Applicability to kinds of optical fibers } \\
\text { + Low cost } \\
\text { + Grating formed with good temperature stability } \\
\text {-Poor production consistence } \\
\text {-Low micromachining precision }\end{array}$ & Only LPFG \\
\hline Chemical etching & $\begin{array}{l}\text { +Low fabrication cost } \\
\text {-Grating with bad robustness }\end{array}$ & Only LPFG \\
\hline $\begin{array}{l}\text { Mechine-induced } \\
\text { microbending }\end{array}$ & $\begin{array}{l}\text { +Low fabrication cost } \\
\text {-Hard to control resonant wavelength } \\
\text {-Short life of fiber grating } \\
\text { - Grating with bad robustness }\end{array}$ & Only LPFG \\
\hline
\end{tabular}


sensors [24] and LPFG sensors [20]. According to the waveguide structure, it can be classified into uniform, long-period, tilted [25], chirped [26, 27], phase-shift [28], helical fiber grating [29], etc. The structure schematic diagrams of normal types of fiber grating are shown in Fig. 1. Due to the various fiber varieties, such as single mode fiber (SMF), photonic crystal fiber (PCF), few mode fiber (FMF), multi-core fiber (MCF), D-shaped fiber, and sapphire fiber (SF), the manifold grating structures inscribed in them are formed for applying different single or simultaneous physical parameters sensing. The typical structures of FBG and LPFG sensors and their application are reviewed as follows.

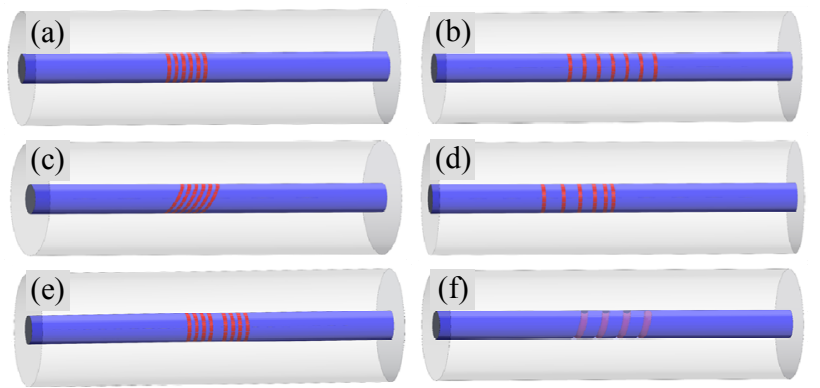

Fig. 1 Sketches of some typical grating structures: (a) uniform, (b) long-period, (c) tilted, (d) chirped, (e) phase-shift, and (f) helical grating structures.

\subsection{FBG sensors}

\subsubsection{FBGs on SMF}

The FBG based on the SMF, where the period of each grating is uniformly distributed along the sensitized region of an optical fiber, is the most commonly and widely used Bragg grating sensor. It is mainly used for temperature and strain sensing and can also be combined with transducer structures to achieve acceleration, force, and pressure measurements. Moreover, in terms of different inscription conditions, FBGs could be further classified into Type I, Type IA, Type II, and Type IIA [30]. Among them, Type I grating [31] is the most widely used type of FBG and is made by using common photosensitive fiber using moderate intensity, but its operation temperature is low, only $200{ }^{\circ} \mathrm{C}$. Type IIA and Type II have the high temperature resistance nearly $500{ }^{\circ} \mathrm{C}$ and $800{ }^{\circ} \mathrm{C}$, respectively. Another high-temperature-resistance grating is regenerated FBG [32, 33], whose periodic index modulation can be regenerated after erasure of the UV-induced Type I grating through thermal annealing. The characteristic comparison of these types of FBG is listed in Table 2. Furthermore, the FBG not only is inscribed in the normal SMF, but also is written on the tapered [34] or misaligned SMF [35] to achieve force or bending parameter measurement. For example, Osuch et al. [26, 27] proposed two novel optical sensors based on linearly tapered and chirped FBGs inscribed by a UV laser, whose grating period co-directionally or counter-directionally is inscribed toward taper end. The inclinometer is characterized by $0^{\circ}-70^{\circ}$ operating range, $1^{\circ}$ resolution and similar sensitivity.

Table 2 Temperature characteristic comparison of normal FBG sensors.

\begin{tabular}{|c|c|c|c|c|}
\hline FBG type & Description & $\begin{array}{c}\text { Temperature sensitivity } \\
\left(\mathrm{pm} /{ }^{\circ} \mathrm{C}\right)\end{array}$ & $\begin{array}{c}\text { Resistance } \\
\text { temperature }\left({ }^{\circ} \mathrm{C}\right)\end{array}$ & Ref. \\
\hline Type I & $\begin{array}{l}\text { Strandard grating, written in both hydrogenated and } \\
\text { non-hydrogenated fibers }\end{array}$ & 9.5 & 200 & {$[31]$} \\
\hline Type IA & $\begin{array}{l}\text { Regenerated grating written after prolonged laser epxposure of a } \\
\text { Type I grating by in hydrogenated fibers }\end{array}$ & 7.0 & / & {$[36]$} \\
\hline Type IIA & $\begin{array}{l}\text { Regenerated grating written after erasing of a Type I grating in } \\
\text { hydrogen free B-Ge and high Ge fibers }\end{array}$ & 10.5 & 500 & {$[37,38]$} \\
\hline Type II & Damage written gratings & l & 800 & {$[37]$} \\
\hline Regenerated & $\begin{array}{l}\text { Regenetated grating formed by high-temperature treatment of } \\
\text { UV-exposed fiber gratings }\end{array}$ & I & 1000 & {$[32,33]$} \\
\hline
\end{tabular}




\subsubsection{FBGs on FMF}

FMF is another typical optical fiber, whose core diameter is larger than that of the SMF but smaller than that of the MMF. Because a few modes can be guided in the FMF, the FBG inscribed in the FMF has several resonate peaks, which could be utilized for various mult-physical parameters measurements. For example, Yang et al. [39] demonstrated a novel
FMF FBG for simultaneous unclad RI and temperature measurement, as shown in Fig. 2. The sensor was inscribed in an FMF with a cladding-less structure made by a chemical etching technique. The sensor had the maximum RI sensitivity of $4.816 \mathrm{~nm} / \mathrm{RIU}$ with the RI range from 1.3159 to 1.3620 , and the maximum temperature of $(9.62 \pm 0.08) \mathrm{pm} /{ }^{\circ} \mathrm{C}$ with the temperature from $22^{\circ} \mathrm{C}$ to $70{ }^{\circ} \mathrm{C}$.
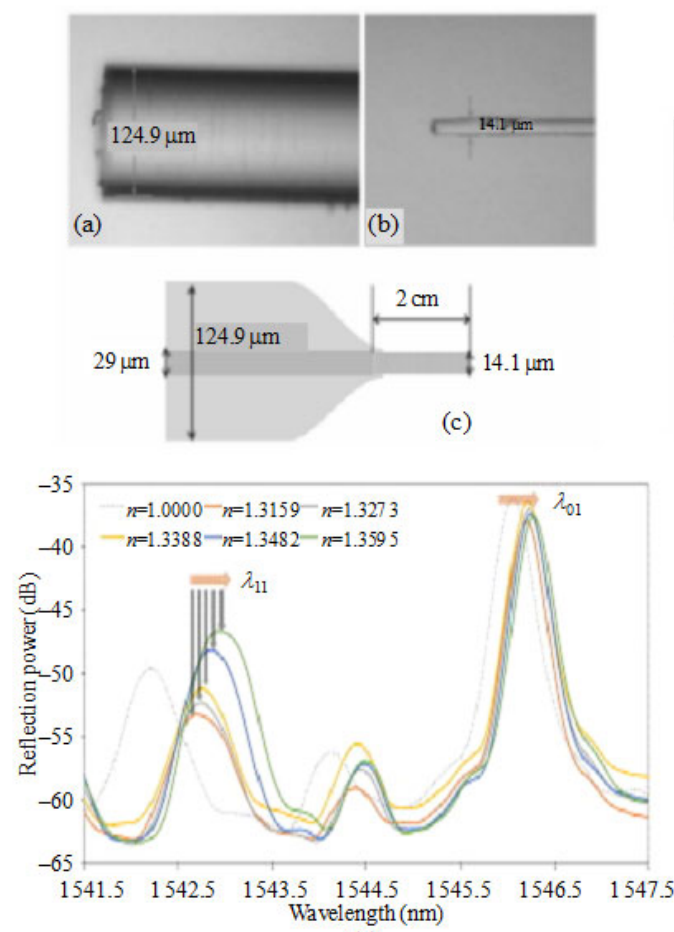

(e)
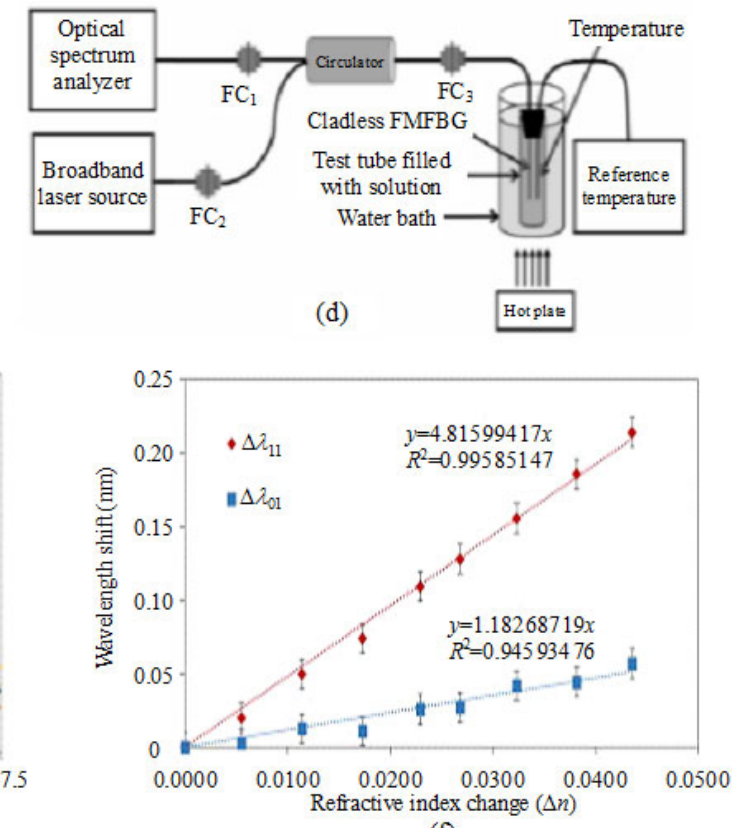

(f)

Fig. 2 Microscope images, experimental setup, and RI response of the FBG sensor based on the FMF [39].

\subsubsection{FBGs on MCF}

Grating structures can be written on single, partial, and all cores of the MCF at the same time for spacial sensing functions. The FBG based on the MCF is easier to achieve curvature measurement due to its performances of multi-dimension and the interaction between different cores. In [40], a robust fiber sensor was formed by splicing a short piece of seven-core fiber with the Bragg grating to the SMF for simultaneous measurement of curvature and temperature, as shown in Fig. 3 And its curvature sensitivity was $-7.27 \mathrm{~dB} / \mathrm{m}^{-1}$ with a linearity of 0.997 in the curvature range of $0 \mathrm{~m}^{-1}-1 \mathrm{~m}^{-1}$ and temperature sensitivity of $12 \mathrm{pm} /{ }^{\circ} \mathrm{C}$. This sensor was insensitive to RI and showed the good stability of curvature. However, the measurement range curvature was a little small. Barrera et al. [25] firstly proposed that the tilted FBGs were selectively inscribed in partial cores of a seven-core fiber by argon-ion laser. This implement could measure the 
strain and curvature parameters with a sensitivity of $1.187 \mathrm{pm} / \mu \varepsilon$ and $70 \mathrm{pm} / \mathrm{m}^{-1}$, respectively. Moreover, this group also presented that each core in a

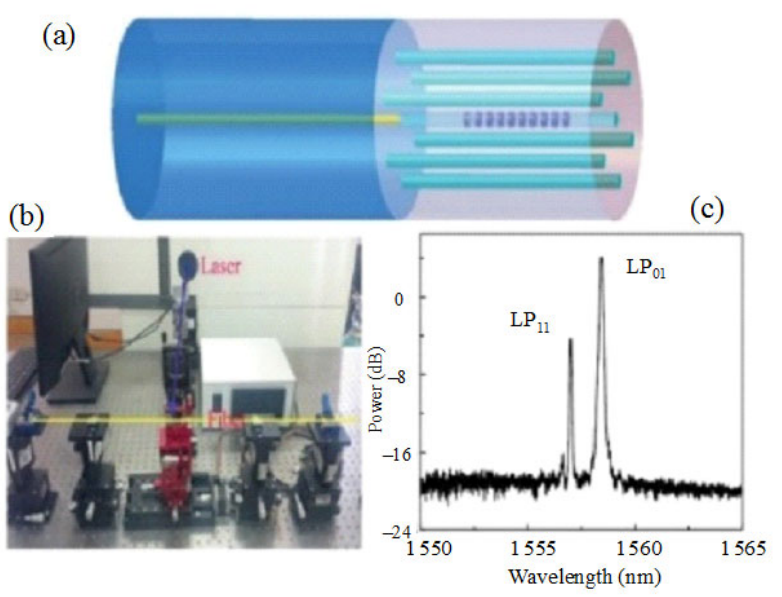

non-twist homogeneous four-core fiber was simultaneously inscribed an FBG to achieve the two-dimensional curvatures measurement [41].

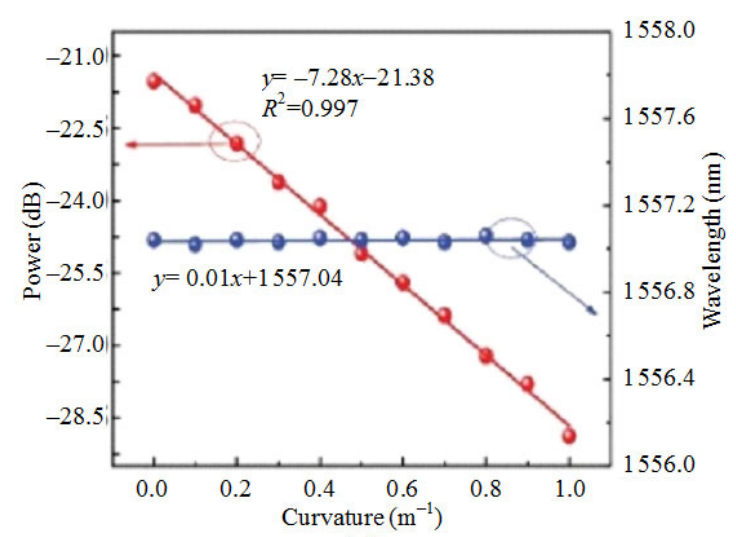

(d)

Fig. 3 Schematic diagram and experimental setup of the FBG sensor based on the MMF and its curvature response [25].

\subsubsection{FBGs on PCF}

FBGs could also be inscribed in PCFs. However, the challenging of cladding scattering and distortion hampers the efficiency in building high quality PCF gratings. Wang et al. [42] reported a new method for high quality FBG inscription in commercial all-silica PCFs by selectively inflating a section of the PCF and formed a three-hole suspended-core fiber (SCF), as shown in Fig. 4. Only one obvious dip was observed in the transmission spectrum of the optical implement with $4.5 \mathrm{~mm}$ core diameter in the SCF region. The static temperature and strain

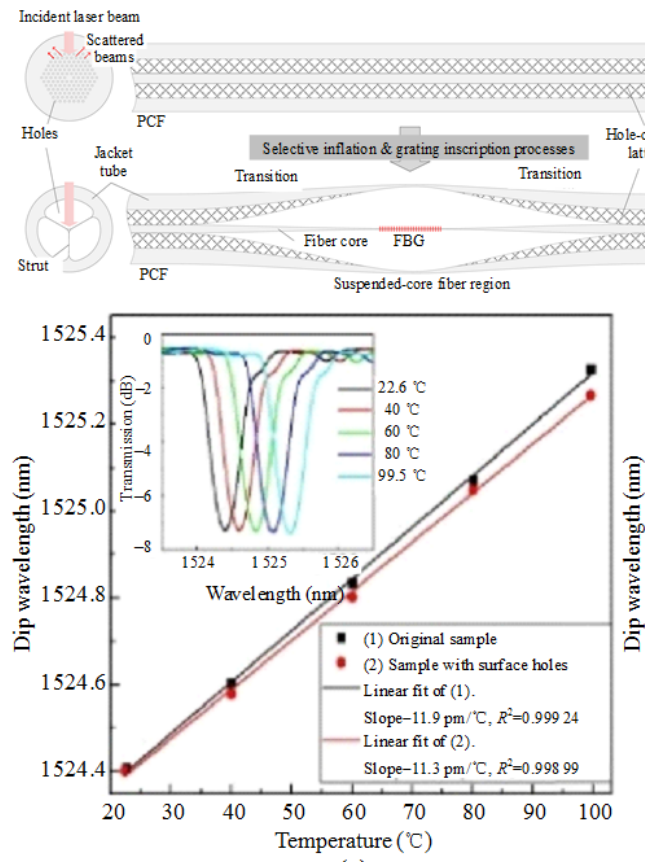

(a)
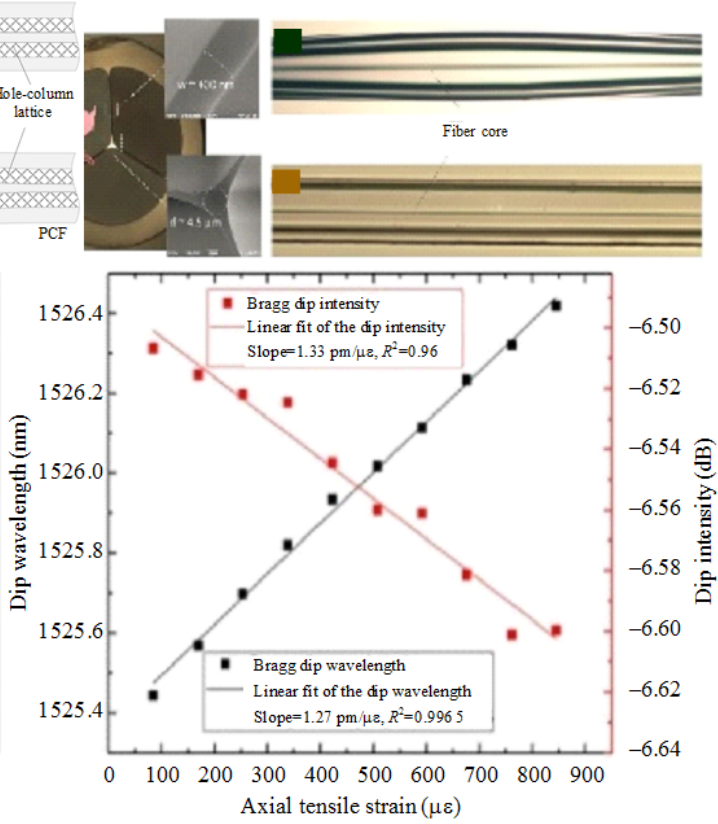

(b)

Fig. 4 Schematic diagram and micrograph of the FBG sensor based on the PCF and its temperature and strain response [42]. 
responses of this structure were respectively $11.3 \mathrm{pm} /{ }^{\circ} \mathrm{C}$ and $1.3 \mathrm{pm} / \mu \varepsilon$, which were comparable to the sensitivities of the FBGs on the commercial SMF. Zhang and Peng also [43] proposed an optical implement from measuring strain and temperature by simultaneously inscribing FBGs in a dual-core PCF, and the maximum temperature and strain responses were respectively $11.88 \mathrm{pm} /{ }^{\circ} \mathrm{C}$ in the range from $20{ }^{\circ} \mathrm{C}$ to $200{ }^{\circ} \mathrm{C}$ and $1.03 \mathrm{pm} / \mu \varepsilon$ in the range from $0 \mu \varepsilon$ to $1000 \mu \varepsilon$. For the simultaneous measurement of curvature and temperature, Wu et al. [44] reported on a compact sensor by integrating an MZI and a cladding Bragg grating in a same section of all-solid photonic bandgap fiber (PBF).

\subsubsection{FBGs on D-shaped fiber}

D-shaped optical fiber has a large evanescent field, which makes the modal propagation constant of the fiber be sensitive to the changes of the surrounding RI. The FBG based on the D-shaped fiber can combines with the MZI structure or sensitive film to achieve curvature and biosensing. For example, Jiang et al. [45] proposed a fiber MZI with the D-shaped FBG configuration for curvature measurement. A segment of D-shaped fiber was fusion spliced into an SMF at both sides, and then a short FBG was inscribed in the D-shaped fiber. This fiber device had a high curvature sensitivity of $87.7 \mathrm{~nm} / \mathrm{m}^{-1}$ in the range from $0 \mathrm{~m}^{-1}$ to $0.3 \mathrm{~m}^{-1}$. Yao et al. [46] proposed and demonstrated a state-of-the-art graphene-based D-shaped polymer FBG by covering a layer of highly p-doped graphene on the surface of a polished and D-shaped section of a micro-structured poly methyl methacrylate (PMMA) polymer FBG to detect the concentration of human erythrocytes, as shown in Fig. 5 This structure showed a maximum surrounding erythrocytes sensitivity over $1 \mathrm{pm} / \mathrm{ppm}$.
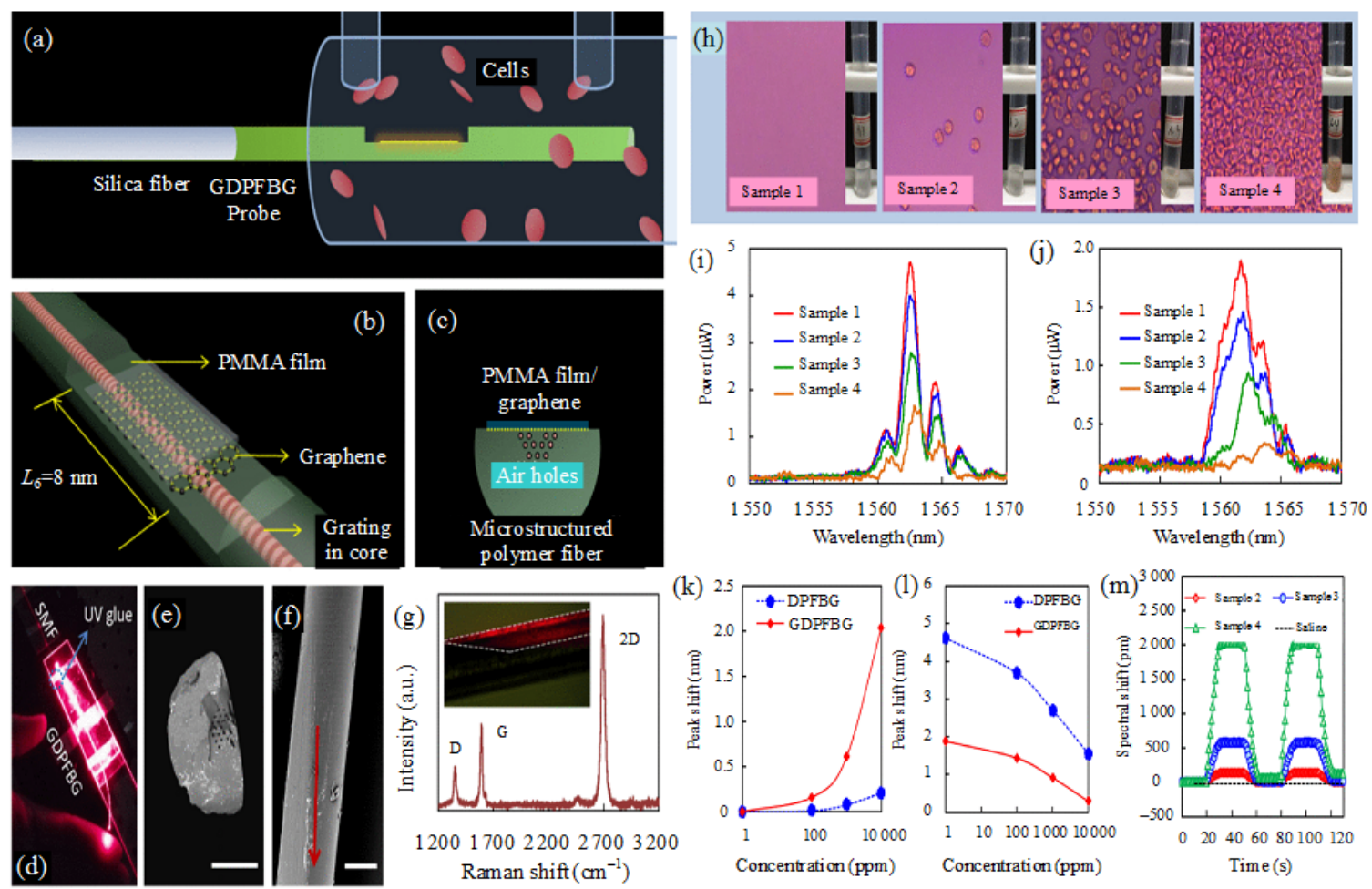

Fig. 5 Schematic diagram of the graphene-based D-shaped polymer FBG (GDPFBG) probe and its experimental results for RBC concentration sensing [46]. 


\subsubsection{FBGs on SF}

The excellent optical transparency, thermal and chemical stability, mechanical robustness, and high melting temperature $\left(2040^{\circ} \mathrm{C}\right)$ of SFs make them a strong candidate for high-temperature environment applications. Since the SF is not a photosensitive material, the grating inscription technique on the SF cannot use the UV exposure method and often use fs laser micromachining. Grobnic et al. [47] reported the first reflective sapphire fiber Bragg grating (SFBG) in a 25 -cm-long $150-\mu \mathrm{m}$-diameter $\mathrm{SF}$ fabricated using $800 \mathrm{~nm}$ fs and a phase mask. Its temperature sensitivity was $30 \mathrm{pm} /{ }^{\circ} \mathrm{C}$. However, the reflection peak of the SFBG had a large 3-dB bandwidth of $6 \mathrm{~nm}$, which not only degraded the measurement accuracy of the SFBG sensor but also limited the multiplexing capability of the SFBGs. This group [48] also reported a single and low-order mode interrogation of SFBGs using a tapered SMF. This tapered-fiber probe approach greatly improved the coupling of the fundamental mode in SFs and reduced the $3-\mathrm{dB}$ bandwidth of its reflective peak to $0.33 \mathrm{~nm}$. Besides, another high-order-mode rejection approach was to inscribe the SFBG in ultra-thin SF (60 $\mu \mathrm{m}$ diameter) [49]. A good resonance peak with a 3-dB bandwidth of $2 \mathrm{~nm}$ was obtained and the grating was tested up to $1600{ }^{\circ} \mathrm{C}$. In addition, a 50-m-long MMF $(105 / 125 \mu \mathrm{m}, \mathrm{NA}=0.22)$ was used as the lead fiber to excite all guided modes in the $100-\mu \mathrm{m}$-diameter 1-m-long SF [50]. This structure could obtain a stable and smooth reflection spectrum, which was also less sensitive to the perturbation along the lead fibers. In addition, three SFBGs with different Bragg wavelengths were successfully inscribed in a $125-\mu \mathrm{m}$-diameter SF by using the fs laser point-by-point method [51]. Narrow peak was obtained from the reflection spectrum as the diameter of the SF was etched to $9.6 \mu \mathrm{m}$. Furthermore, a line-by-line scanning technique was proposed to increase the total reflectivity of an
SFBG [52].

The sensing characteristics of different FBG-based FOM sensors are compared in Table 3.

\subsection{LPFG sensors}

\subsubsection{LPFGs on SMF}

Due to the long grating period of the LPFG, it does not require high precision in the production equipment. Beside the expensive excimer laser, fs laser, $\mathrm{CO}_{2}$ laser, and ion implantation micromachining equipment, the arc discharge and mechanical damage methods $[53,54]$ can also be used for fabricating the LPFG. In addition, the single tilted [55], phased-shift [28], chirped [56], twisted [57], and helical LPFGs [58] can be inscribed on an SMF, but also multiple LPFGs can be cascaded. For example, Wang and Rao [59] proposed a bend-sensor, consisting of one LPFG induced by UV laser and two LPFGs induced by high-frequency $\mathrm{CO}_{2}$ laser pulses, which could not only directly measure curvature, but also uniquely determine every bend-direction within the circular range of $0^{\circ}-$ $360^{\circ}$. The sensing principle of this structure was based on the fact that the resonant wavelength bend-sensitivity of LPFGs induced by high-frequency $\mathrm{CO}_{2}$ laser pulses depended strongly on the bending-directions, the resonant wavelength of common LPFGs induced by UV laser shifted linearly with the bending, and its bend-sensitivity was independent on the bend-directions. Geng et al. [60] proposed a bending vector sensor based on spatial cascaded orthogonal LPFGs written by high-frequency $\mathrm{CO}_{2}$ laser pulses. But this sensor was insensitive when the curvature magnitude was below $0.5 \mathrm{~m}^{-1}$. Besides, Li et al. [61] proposed and demonstrated a novel dual-parameter measurement scheme based on a cascaded LPFG and an S fiber taper MZI, as shown in Fig. 6. The temperature and RI sensitivities of the LPFG and MZI were $-52.27 \mathrm{~nm} / \mathrm{RIU}$ and $45.87 \mathrm{pm} /{ }^{\circ} \mathrm{C}, 311.48 \mathrm{~nm} / \mathrm{RIU}$, and $12.87 \mathrm{pm} /{ }^{\circ} \mathrm{C}$, respectively. 
Table 3 Sensing characteristics comparison of different FBG-based FOM sensors.

\begin{tabular}{|c|c|c|c|}
\hline Structure & Inscribed technology & Main sensing characteristics & Ref. \\
\hline FBG on SMF & UV laser & $\begin{array}{l}\text { Temperature sensitivity: } 9.5 \mathrm{pm} /{ }^{\circ} \mathrm{C} \\
\text { Highest operation temperature: } 200{ }^{\circ} \mathrm{C}\end{array}$ & {$[30]$} \\
\hline FBG on SMF & Fs laser & $\begin{array}{l}\text { Temperature sensitivity: } 15.5 \mathrm{pm} /{ }^{\circ} \mathrm{C} \\
\text { Highest operation temperature: } 700{ }^{\circ} \mathrm{C}\end{array}$ & {$[6]$} \\
\hline FBG on multimode air-clad SF & Fs laser & $\begin{array}{l}\text { Temperature sensitivity: } 1900 \mathrm{pm} /{ }^{\circ} \mathrm{C} \\
\text { Reproducibility: better than } \pm 2 \mathrm{~K}\end{array}$ & [62] \\
\hline $\begin{array}{l}\text { FBG on a micro-single-crystal sapphire } \\
\text { fiber }\end{array}$ & Fs laser & $\begin{array}{l}\text { Temperature sensitivity: } 25.6 \mathrm{pm} /{ }^{\circ} \mathrm{C} \\
\text { Operating temperature up to } 1400{ }^{\circ} \mathrm{C}\end{array}$ & [63] \\
\hline SMF-FBG-SMF & Fs laser & $\begin{array}{l}\text { Temperature sensitivity: } 479.48 \mathrm{pm} /{ }^{\circ} \mathrm{C} \text { for the temperature range of } 60{ }^{\circ} \mathrm{C} \\
\text { to } 95{ }^{\circ} \mathrm{C}\end{array}$ & {$[64]$} \\
\hline FBG on a dual-core PCF & UV laser & $\begin{array}{l}\text { Strain sensitivity: } 1.03 \mathrm{pm} / \mu \varepsilon \\
\text { Temperature sensitivity: } 11.88 \mathrm{pm} /{ }^{\circ} \mathrm{C}\end{array}$ & [43] \\
\hline FBG on twin-core FMF & Fs laser & Bending sensitivity: $-37.41 \mathrm{pm} / \mathrm{m}^{-1}$ & [19] \\
\hline $\begin{array}{l}\text { An array of FBGs inscribed in a } \\
\text { four-core fiber }\end{array}$ & UV laser & Standard error: under $1.6 \%$ in the curvature range of $2.9 \mathrm{~m}^{-1}-26.17 \mathrm{~m}^{-1}$ & [41] \\
\hline FBG on D-shaped fiber & Fs laser & $\begin{array}{l}\text { RI sensitivity: } 30 \mathrm{~nm} / \mathrm{RIU} \\
\text { Temperature sensitivity: } 9 \mathrm{pm} /{ }^{\circ} \mathrm{C}\end{array}$ & {$[65]$} \\
\hline FBGs on multicore fiber & Fs laser & Bending sensitivity: $-37.41 \mathrm{pm} / \mathrm{m}^{-1}$ & [19] \\
\hline Tilted FBG on D-shaped fiber & / & RI sensitivity: from $1000 \mathrm{nW} / \mathrm{RIU}$ to $13000 \mathrm{nW} / \mathrm{RIU}$ & {$[66]$} \\
\hline Tilted moiré FBG & UV laser & $\begin{array}{l}\text { RI sensitivities: } 574.229 \mathrm{~nm} / \mathrm{RIU} \\
\text { Measuring resolution: } 2 \times 10^{-7} \mathrm{RIU}\end{array}$ & {$[67]$} \\
\hline Multi-angle tilted FBG & UV laser & $\begin{array}{l}\text { RI sensitivity: } 500 \mathrm{~nm} / \mathrm{RIU} \\
\text { Measuring range: } 1.15 \mathrm{RIU}-1.45 \mathrm{RIU}\end{array}$ & {$[68]$} \\
\hline Tilted FBG on multicore fiber & UV laser & $\begin{array}{l}\text { Magnitude and wavelength curvature sensitivity: } 25 \mathrm{~dB} / \mathrm{m}^{-1} \text { and } \\
70 \mathrm{pm} / \mathrm{m}^{-1} \text {, respectively }\end{array}$ & {$[25]$} \\
\hline Chirped FBG on SMF & / & Temperature sensitivity: $10.2 \mathrm{pm} /{ }^{\circ} \mathrm{C}$ & [69] \\
\hline Regenerated chirped FBG & UV laser & Temperature sensitivity: $15.1 \mathrm{pm} /{ }^{\circ} \mathrm{C}$ & [70] \\
\hline Phase-shift FBG on SMF & / & Limited detectable dynamic strain: $8.7 \mu \varepsilon$ & [71] \\
\hline Phase-shift FBG on SMF & UV laser & Strain sensitivity: $5 \mathrm{p} \varepsilon / \sqrt{ } \mathrm{Hz}$ & {$[72]$} \\
\hline
\end{tabular}
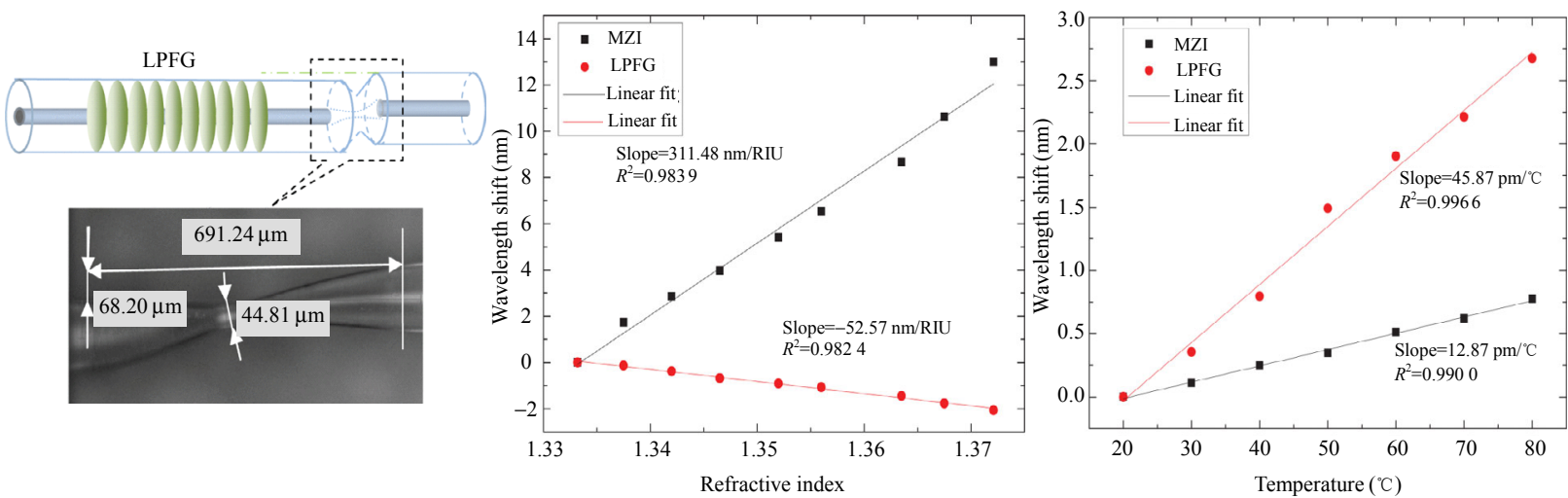

Fig. 6 Schematic diagram and SEM image of the cascaded fiber device and its RI and temperature responses [61].

\subsubsection{LPFGs on FMF}

Similar to the LPFG based on the SMF structures, the LPFG structures based on the FMF can be written on the fiber, or multiple different LPFGs to form a cascaded structure. An LPFG inscribed in an FMF by using a $\mathrm{CO}_{2}$ laser was firstly proposed by Wang et al. [73]. Its transmission spectra shifted to shorter wavelength direction with the increment of strain and the sensitivity of the resonant peak was $-4.5 \mathrm{pm} / \mu \varepsilon$, which was more than one order of magnitude higher than that of the LPFG based on the SMF. Then, this group [74] also 
proposed a cascaded structure of two LPFGs for simultaneous measurement of strain and temperature, as shown in Fig. 7. The two cascaded LPFGs were inscribed in a standard SMF and an FMF by using a
$\mathrm{CO}_{2}$ laser, respectively. The FMF-LPFG and the SMF-LPFG displayed different sensitivities of strain and temperature, which were $-2.9 \mathrm{pm} / \mu \varepsilon$ and $-17.6 \mathrm{pm} /{ }^{\circ} \mathrm{C},-1.47 \mathrm{pm} / \mu \varepsilon$, and $46.4 \mathrm{pm} /{ }^{\circ} \mathrm{C}$, respectively.
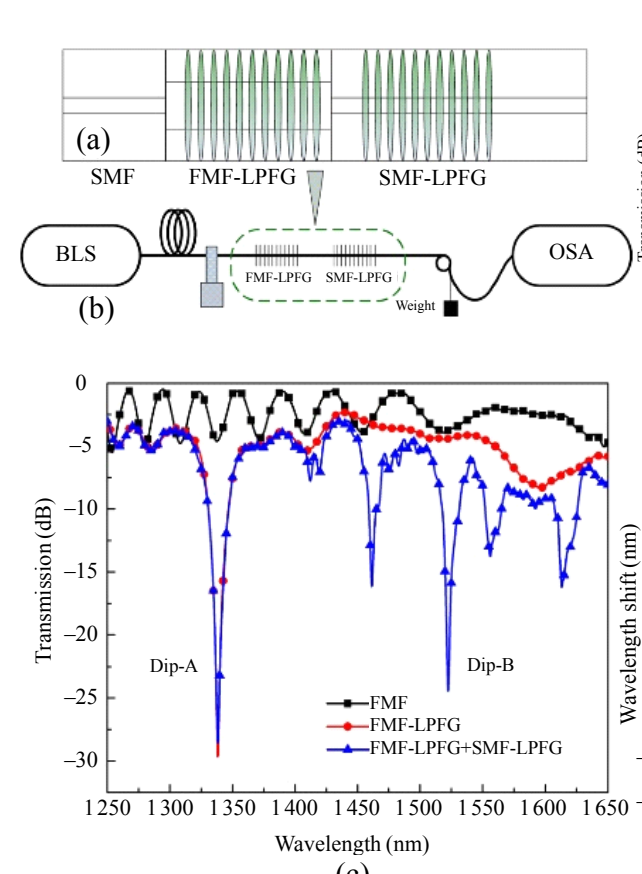

(c)
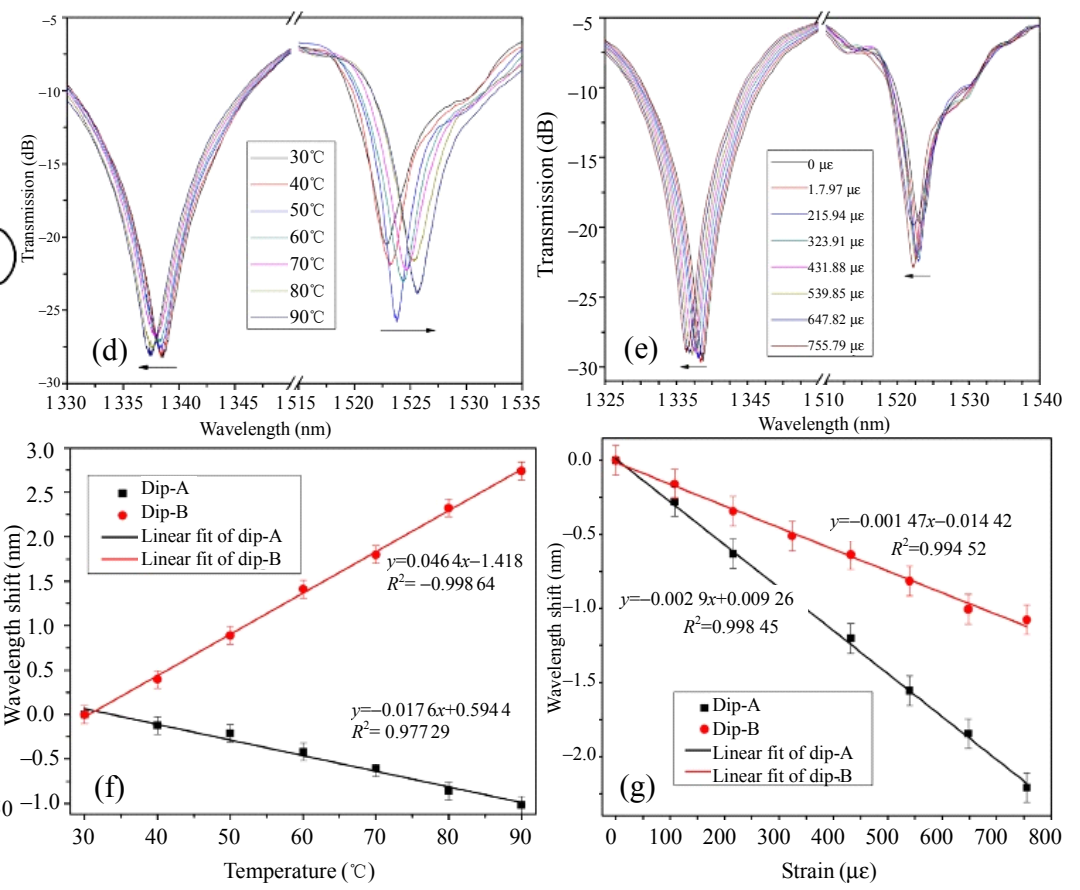

Fig. 7 Schematic diagrams and experimental setup of the dual-LPFG sensor, and its temperature and strain responses [74].

\subsubsection{LPFGs on MCF}

The LPFGs based on MCF structures are manifold since the cores of the MCF have a different distribution. The LPFGs can be written on different cores of the MCF in a cascade or parallel manner. For example, Barrera et al. [75] inscribed a set of three different LPFGs in a seven-core optical fiber using a selective inscription technique for directional curvature measurement, a single LPFG in the external cores, and an array of three LPFGs in the central core. This sensor showed a linear response for curvature magnitudes from $0 \mathrm{~m}^{-1}$ to $1.77 \mathrm{~m}^{-1}$ with a maximum curvature sensitivity of $-4.85 \mathrm{~nm} / \mathrm{m}^{-1}$ and a near sinusoidal behavior in all the cores with curvature directions from $0^{\circ}$ to $60^{\circ}$. Xiang et al. [76] demonstrated a helical LPFG manufactured from the MCF combined with twist and $\mathrm{CO}_{2}$ laser heating technology, as shown in Fig. 8. The nineteen cores of the MCF behaved as a kind of
SMF and were distributed hexagonally which made the helical structure only exist in the core area after heating and twisting. This sensor displayed a high twist sensitivity of approximately $0.2 \mathrm{~nm} /(\mathrm{rad} / \mathrm{m})$ and showed a potential for use as an RI sensor.

\subsubsection{LPFGs on PCF}

The LPFG based on the PCF not only is used as common sensors but also can combinate with filling techniques for enriching its applications. For example, Zhang et al. [77] proposed an inline optofluidic RI sensor formed by splicing a side-channel PCF with side-polished SMF. An LPFG was written on the side-channel PCF to provide high sensitivity for monitoring the RI variation of the liquid flow in the side-channel, as shown in Fig. 9. This sensor achieved a broad RI response from 1.3330 to 1.3961 of the liquid circulated in the side-channel PCF and an 
approximately linear response at a low RI range over $1.3330-1.3780$ with the sensitivity of $1145 \mathrm{~nm} / \mathrm{RIU}$. Du et al. [78] proposed and demonstrated a temperature sensor based on an isopropanol-filled PCF-LPFG. Due to the high thermo-optic coefficient of isopropanol, the sensitivity of the proposed temperature could be effectively improved by filling isopropanol in the waveguides of the PCF. And the temperature sensitivity of this sensor was $1.356 \mathrm{~nm} /{ }^{\circ} \mathrm{C}$ in the range of $20^{\circ} \mathrm{C}$ to $50{ }^{\circ} \mathrm{C}$. In addition, He et al. [79] inscribed the LPFG in an air-filled and a water-filled PCF by a $\mathrm{CO}_{2}$ laser for measuring the $\mathrm{RI}$ of $\mathrm{NaCl}$ solution. The RI detection resolutions of the air-filled and water-filled sensors were $3.34 \times 10^{-7}$ RIU and $4.42 \times 10^{-7}$ RIU, respectively.
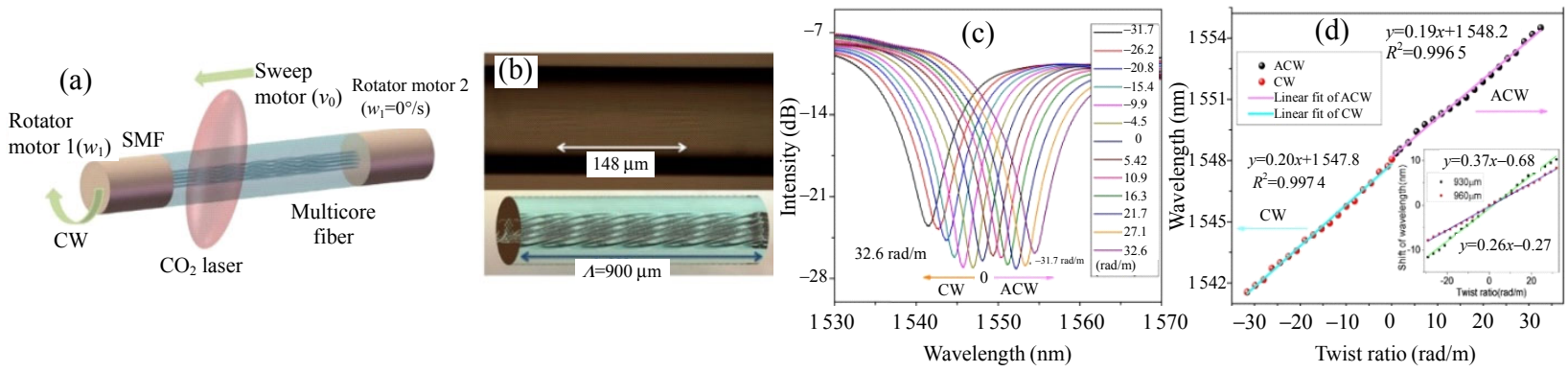

Fig. 8 Schematic diagram and micrograph of the helical LPG based on the MCF and its twist response [76].
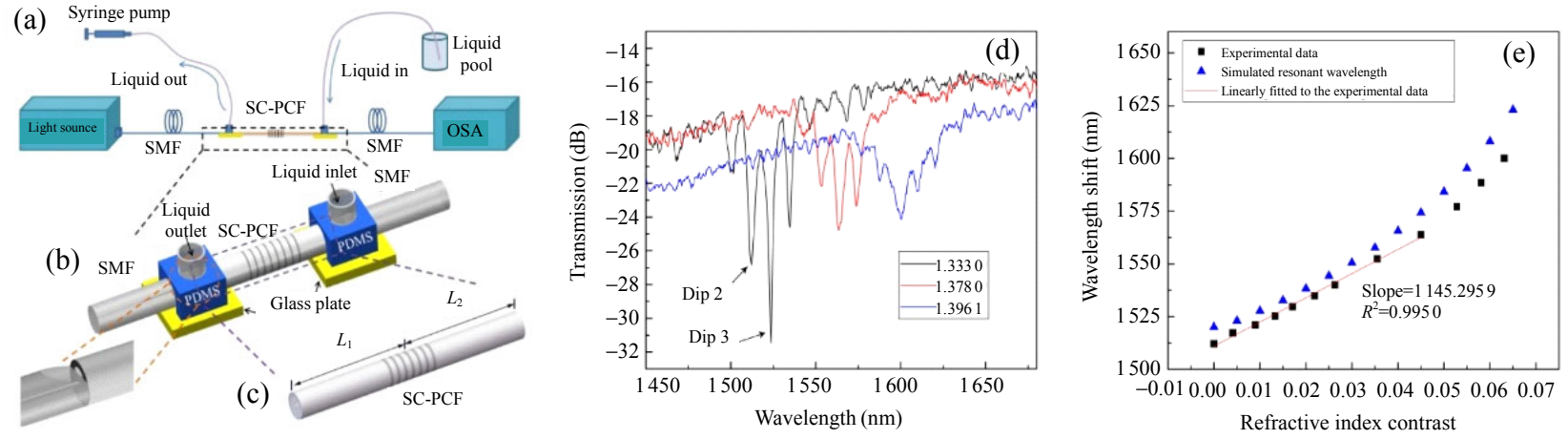

Fig. 9 Schematic diagrams of the inline optofluidic sensing platform and RI response of the LPFG sensor based on the PCF [77].

\subsubsection{LPFGs on D-shaped fiber}

Tripathi et al. [80] presented a theoretical study of the ambient RI sensing characteristics of LPFGs in bare and metal-coated D-shaped fibers. The study showed that the dual resonances could be shifted to lower wavelengths by increasing (decreasing) the metal thickness and the detection of RI changes was only $1.67 \times 10^{-7}$ RIU. Quero et al. [81] proposed a self-functionalized and high sensitivity LPFG. The sensor consisted of a D-shaped optical fiber fabricated by wet chemical etching and an LPFG fabricated by a UV laser periodically writing the polystyrene located on the flat surface on the fiber. The transmission peak shifted about $28 \mathrm{~nm}$ and 41 $\mathrm{nm}$ for the water RI and the liquid with $1.36 \mathrm{RIU}^{-1}$. And its sensitivity could be adjusted by controlling the high RI overlay and the wet chemical etching step. In addition, Gao et al. [3] proposed a magnetic sensor utilizing LPFG written by high-frequency $\mathrm{CO}_{2}$ laser pulses in a D-shaped fiber, as shown in Fig. 10. Its magnetic-field sensitivity is $176.4 \mathrm{pm} / \mathrm{mT}$.

The sensing characteristics of different LPFG-based FOM sensors are compared in Table 4. 

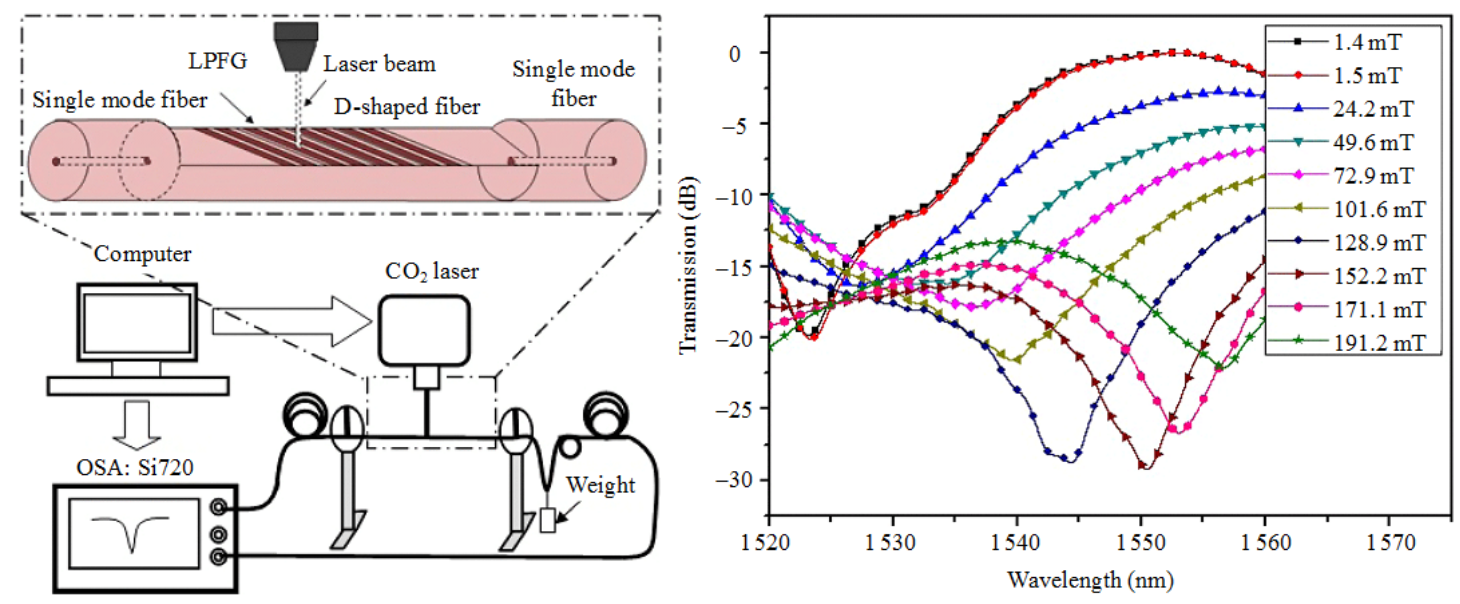

Fig. 10 Schematic diagram of the system for fabricating LPFG in D-shaped fiber and its magnetic-field response [3].

\section{FPI sensors}

An FPI, sometimes called as an etalon, is generally consisted of two parallel reflecting surfaces separated by a certain distance. Interference occurs due to the multiple superpositions of both reflected and transmitted beams at two parallel surfaces. FPI sensors can be generally classified into categories: the intrinsic and extrinsic Fabry-Perot interferometer sensors (IFPI and EFPI) according to the behaviors of the light in the cavity. The schematic diagrams of the EFPI and the IFPI are shown in Figs. 11(a) and 11(b), respectively. EFPI allows light exit from the fiber and be modulated in a different media before being coupled into the optical fiber. In IFPI, the media of the FP cavity is the optical fiber itself, which does not only act as a waveguide to transmit light but also an interferometric cavity modulating the light. A measurand as a perturbation to the FPI sensor changes its reflected or transmission spectrum by affecting the optical length $(L)$ and the RI of the FP cavity and then is acquired by demodulating the spectrum variation of the FPI sensors. The kinds of EFPI and IFPI structures will be introduced in the below section.

\subsection{Typical IFPI structures}

The IFPI sensors often consist of two reflecting elements and a section of the SMF in between, and it be classified into two types: the inline-type IFPI and the tip-type IFPI structures (I-IFPI and T-IFPI).

\subsubsection{Inline-type IFPIs}

For I-IFPI, the reflective surface of the FP can be formed by thin dielectric films, FBG pairs, small air holes, and splicing surface between different kinds of fiber, as shown in Figs. 12(a) to 12(d), respectively.

For I-IFPI based on reflective films [82], its fabrication process mainly includes two steps: coating a thin dielectric film on a cleaved end face of fiber, then fusion splicing the coated fiber, and the other cleaving uncoated fiber to form an inline mirror. The reflective film coated on the optical fiber can be fabricated by the vacuum deposition, magnetron sputtering, or e-beam evaporation and thousands of optical fibers can be coated at one time with the same reflective spectral performance. However, it is still challenging to form an intact inline reflective film since the film may distort and the reflectance may decrease greatly during the fusion splice. At present, the material of the thin dielectric film is often used such as $\mathrm{TiO}_{2}, \mathrm{SiO}_{2}$ or $\mathrm{Cr}$ [83] and the inline-IFPI sensors based on $\mathrm{TiO}_{2}$ or $\mathrm{SiO}_{2}$ film are used for temperature sensing from $-200{ }^{\circ} \mathrm{C}$ to $1050{ }^{\circ} \mathrm{C}$. 
Table 4 Sensing characteristics comparison of different LPFG-based FOM sensors.

\begin{tabular}{|c|c|c|c|}
\hline Structure & Inscribed technology & Main sensing characteristics & Ref. \\
\hline LPFG inscribed on SMF & $\mathrm{CO}_{2}$ laser & $\begin{array}{l}\text { Strain sensitivity: }-7.6 \mathrm{pm} / \mu \varepsilon \\
\text { Temperature sensitivity: } 3.91 \mathrm{pm} /{ }^{\circ} \mathrm{C}\end{array}$ & [84] \\
\hline LPFG formed by periodic grooves & $\mathrm{CO}_{2}$ laser & $\begin{array}{l}\text { Temperature measurement resolution: } 0.1{ }^{\circ} \mathrm{C} \text { in the range of } 20{ }^{\circ} \mathrm{C} \text { to } \\
100{ }^{\circ} \mathrm{C}\end{array}$ & [85] \\
\hline Grooved LPFG & $\mathrm{CO}_{2}$ laser & $\begin{array}{l}\text { Resonant peak shift: } \sim 22 \mathrm{~nm} \text { when the surrounding RI varies in the range } \\
\text { of } 1.33-1.45\end{array}$ & [54] \\
\hline LPFG formed by rotary grooves & $\mathrm{CO}_{2}$ laser & Strain sensitivity: $(0.1067 \pm 0.0075) \mathrm{nm} / \mu \varepsilon$ & [86] \\
\hline LPFG on micro-core-offsets structure & Cleaving-splicing & $\begin{array}{l}\text { Temperature sensitivity: } 47 \mathrm{pm} /{ }^{\circ} \mathrm{C} \\
\text { Torsion sensitivity: } 23 \mathrm{pm} /(\mathrm{rad} / \mathrm{m}) \\
\text { RI sensitivity: } 5.25 \mathrm{~nm} / \mathrm{RIU}\end{array}$ & [53] \\
\hline $\begin{array}{l}\text { LPFG inscribed on a two-core hollow } \\
\text { eccentric fiber }\end{array}$ & $\mathrm{CO}_{2}$ laser & $\begin{array}{l}\text { Temperature sensitivity: } \sim 55 \mathrm{pm} /{ }^{\circ} \mathrm{C} \\
\text { Bending response: } \sim 0.6 \mathrm{~nm} / \mathrm{m}^{-1}\end{array}$ & [87] \\
\hline LPFG inscribed on FMF & $\mathrm{CO}_{2}$ laser & $\begin{array}{l}\text { Strain sensitivity: }-4.5 \mathrm{pm} / \mu \varepsilon \\
\text { Temperature sensitivity: }-28.36 \mathrm{pm} /{ }^{\circ} \mathrm{C}\end{array}$ & [73] \\
\hline Tapered LPFG on SMF & $\mathrm{CO}_{2}$ laser & $\begin{array}{l}\text { Strain sensitivities: } 1.82 \mathrm{pm} / \mu \varepsilon \text { and } 8.17 \mathrm{pm} / \mu \varepsilon \\
\text { Temperature sensitivities: } 47.9 \mathrm{pm} /{ }^{\circ} \mathrm{C} \text { and } 65 \mathrm{pm} /{ }^{\circ} \mathrm{C}\end{array}$ & [88] \\
\hline Tapered LPFG on SMF & Arc discharge & $\begin{array}{l}\text { Pressure sensitivity: } 5.1 \mathrm{pm} / \mathrm{bar} \\
\text { Temperature sensitivity: } 50 \mathrm{pm} /{ }^{\circ} \mathrm{C}\end{array}$ & [89] \\
\hline Tapered LPFG on PCF & Arc discharge & $\begin{array}{l}\text { Pressure sensitivity: } 11.2 \mathrm{pm} / \mathrm{bar} \\
\text { Temperature sensitivity: } 0.3 \mathrm{pm} /{ }^{\circ} \mathrm{C}\end{array}$ & [90] \\
\hline LPFG on PCF & UV laser & $\begin{array}{l}\text { RI sensitivity: } 2343 \mathrm{~nm} / \mathrm{RIU} \\
\text { An analytical resolution: } 8.5 \times 10^{-6} \mathrm{RIU}\end{array}$ & [91] \\
\hline LPFG on air-core PBF & $\mathrm{CO}_{2}$ laser & Pressure sensitivity: $-137 \mathrm{pm} / \mathrm{MPa}$ & [92] \\
\hline LPFG on all-solid PBF & Fs laser & RI sensitivity: $537 \mathrm{~nm} / \mathrm{RIU}$ in the range of $1.30 \mathrm{RIU}-1.35 \mathrm{RIU}$ & [93] \\
\hline LPFG on periodic microchannels & Fs laser & $\begin{array}{l}\text { RI sensitivity: }-692 \mathrm{~nm} / \mathrm{RIU} \text { or } 1289 \mathrm{~dB} / \mathrm{RIU} \\
\text { Temperature sensitivity: } 9.95 \mathrm{pm} /{ }^{\circ} \mathrm{C}\end{array}$ & [94] \\
\hline Helical LPFG on SMF & Arc discharge & $\begin{array}{l}\text { Temperature sensitivity: } 70 \mathrm{pm} /{ }^{\circ} \mathrm{C} \\
\text { Twist sensitivity: }-46.46 \mathrm{~nm} /(\mathrm{rad} / \mathrm{mm}) \\
\text { Strain sensitivity: } 1.88 \mathrm{pm} / \mu \varepsilon\end{array}$ & [95] \\
\hline Helical LPFG on SMF & $\begin{array}{l}\text { Hydrogen-oxygen } \\
\quad \text { flame }\end{array}$ & $\begin{array}{l}\text { Temperature sensitivity: } 132.8 \mathrm{pm} /{ }^{\circ} \mathrm{C} \\
\text { Bending sensitivity: } 1.94 \mathrm{~nm} / \mathrm{m}^{-1} \\
\text { Strain sensitivity: } 1.41 \mathrm{pm} / \mu \varepsilon\end{array}$ & [96] \\
\hline Helical LPFG on multicore fiber & $\mathrm{CO}_{2}$ laser & Strain sensitivity: $-61.8 \mathrm{pm} / \mu \varepsilon$ & [97] \\
\hline $\begin{array}{l}\text { Helical LPFG on MMF } \\
\text { Inflated LPFG on PCF }\end{array}$ & $\begin{array}{l}\mathrm{CO}_{2} \text { laser } \\
\mathrm{CO}_{2} \text { laser }\end{array}$ & $\begin{array}{l}\text { Twist sensitivity: } 0.198 \mathrm{~nm} /(\mathrm{rad} / \mathrm{m}) \\
\text { Strain sensitivity: }-5.62 \mathrm{pm} / \mu \varepsilon \\
\text { Temperature sensitivity: } 11.92 \mathrm{pm} /{ }^{\circ} \mathrm{C}\end{array}$ & $\begin{array}{l}{[76]} \\
{[98]}\end{array}$ \\
\hline Inflated LPFG on PCF & $\mathrm{CO}_{2}$ laser & $\begin{array}{l}\text { Pressure sensitivity: } 0.12 \mathrm{~nm} / \mathrm{MPa} \\
\text { Temperature sensitivity: } 3.1 \mathrm{pm} /{ }^{\circ} \mathrm{C}\end{array}$ & [99] \\
\hline Tilted LPFG on PCF & $\begin{array}{l}\text { Mechanical pressing } \\
\text { method }\end{array}$ & Pressure sensitivity: $2.701 \mathrm{~nm} / \mathrm{MPa}$ & [100] \\
\hline Tilted LPFG on SMF & Fs laser & $\begin{array}{l}\text { RI sensitivity: }-602.86 \mathrm{~nm} / \mathrm{RIU} \\
\text { Temperature sensitivity: } 103.8 \mathrm{pm} /{ }^{\circ} \mathrm{C} \\
\text { Twisting sensitivities: } 48.94 \mathrm{~nm} /(\mathrm{rad} / \mathrm{mm}) \\
\text { Strain sensitivities: }-0.63 \mathrm{pm} / \mu \varepsilon\end{array}$ & [101] \\
\hline Two cascaded $6^{\circ}$ tilted LPFGs & $\mathrm{CO}_{2}$ laser & $\begin{array}{l}\text { Bending sensitivity: }-15.4935 \mathrm{~nm} / \mathrm{m}^{-1} \text { and } 15.2852 \mathrm{~nm} / \mathrm{m}^{-1} \text { respectively in } \\
\text { the curvature range of } 0.5 \mathrm{~m}^{-1}-2 \mathrm{~m}^{-1} \text { and opposite bending direction }\end{array}$ & [55] \\
\hline Phase-shift LPFG on SMF & $\mathrm{CO}_{2}$ laser & Strain measurement accuracy: $\pm 30 \mu \varepsilon$ & [102] \\
\hline
\end{tabular}



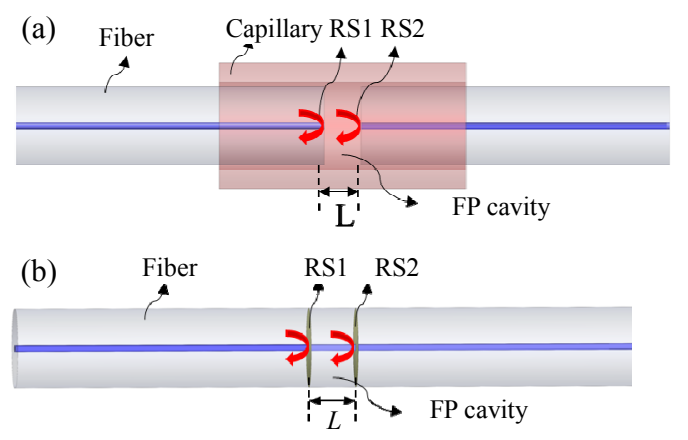

Fig. 11 Schematic diagrams of (a) EFPI sensor with an external air cavity and (b) IFPI sensor formed by two reflecting surfaces, RS1 and RS2, along a fiber. RS1: the first reflective surface; RS2: the second reflective surface.

(a)

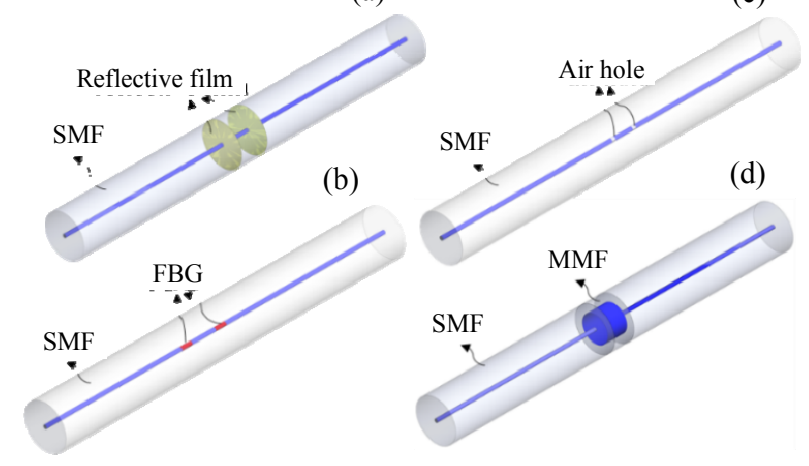

Fig. 12 Configurations of inline-type IFPI based on (a) reflective film, (b) FBG pair, (c) air hole, and (d) MMF.

For I-type IFPI based on the FBG pairs [103], the IFPI sensors can be formed by a pair of FBGs with somewhat reflectance, as shown in Fig. 12(b). The I-IFPI sensor based on the FBG can be used to strain sensing and it can stand strain of up to $12000 \mu \varepsilon$ due to no cleaving and splicing over the sensor region. Moreover, a narrow segment of RI change induced by the UV laser beam can also be acted as an inline FP mirror.

For I-IFPI based on small air holes, the small air hole can be acted as an inline mirror, since the Fresnel reflection between the fiber material and air offers a reflection of about $4 \%$, which is sufficient to form a high-performance mirror for the IFPI sensors based on two-beam interference. There are two structures of the I-IFPI based on small air holes [104]. The first is by using one air-gap mirror and one Fresnel reflection of a cleaved fiber, as a tip-type IFPI structure. It is good for single-point measurement. The other is by using two air-gap mirrors. It is better for multi-point measurement via sensor multiplexing. There are several methods to make a micro-hole at the fiber end face, including chemical etching, laser micromachining technology, and FIB milling. All these methods have been used for fabricating a wide air gap to form an EFPI sensor, which will be introduced in Section 3.2.

For I-IFPI based on fusion splicing of different kinds of fibers, the two reflective mirrors both are formed by fusion splicing surface between two different kinds of fiber, as shown in Fig. 12(d). There is a reflective signal according to the Fresnel equation:

$$
R=\left[\left(n_{1}-n_{2}\right) /\left(n_{1}+n_{2}\right)\right]^{2}
$$

where $n_{1}$ and $n_{2}$ are the RIs of the two optical fibers. Wang and coworkers [105] proposed the inline-IFPI sensor based on splicing of an MMF in two SMFs, that is, the singlemode-multimode-singlemode (SMS) structure, as shown in Fig. 13 The sensor was proved of its potential for distributed temperature and strain measurements.

\subsubsection{Tip-type IFPIs}

For T-IFPI, its structure is formed by splicing two segments fiber with mismatched cores, and its first and second reflecting surfaces are the splicing surface of these two fibers and the cleaved end face of the pigtail fiber, respectively, as shown in Fig.14 The first segment fiber often uses SMF and the second fiber often uses MMF, PCF [106], thin core fiber (TCF) [107], SF [108], and so on [109]. The fabrication process of the tip-type IFPI structure only requires cleaving and splicing, and it is good for high-temperature sensing as the whole structure was based on silica. Especially, the T-IFPI based on the SF can achieve the high temperature sensing with $1500{ }^{\circ} \mathrm{C}$. 


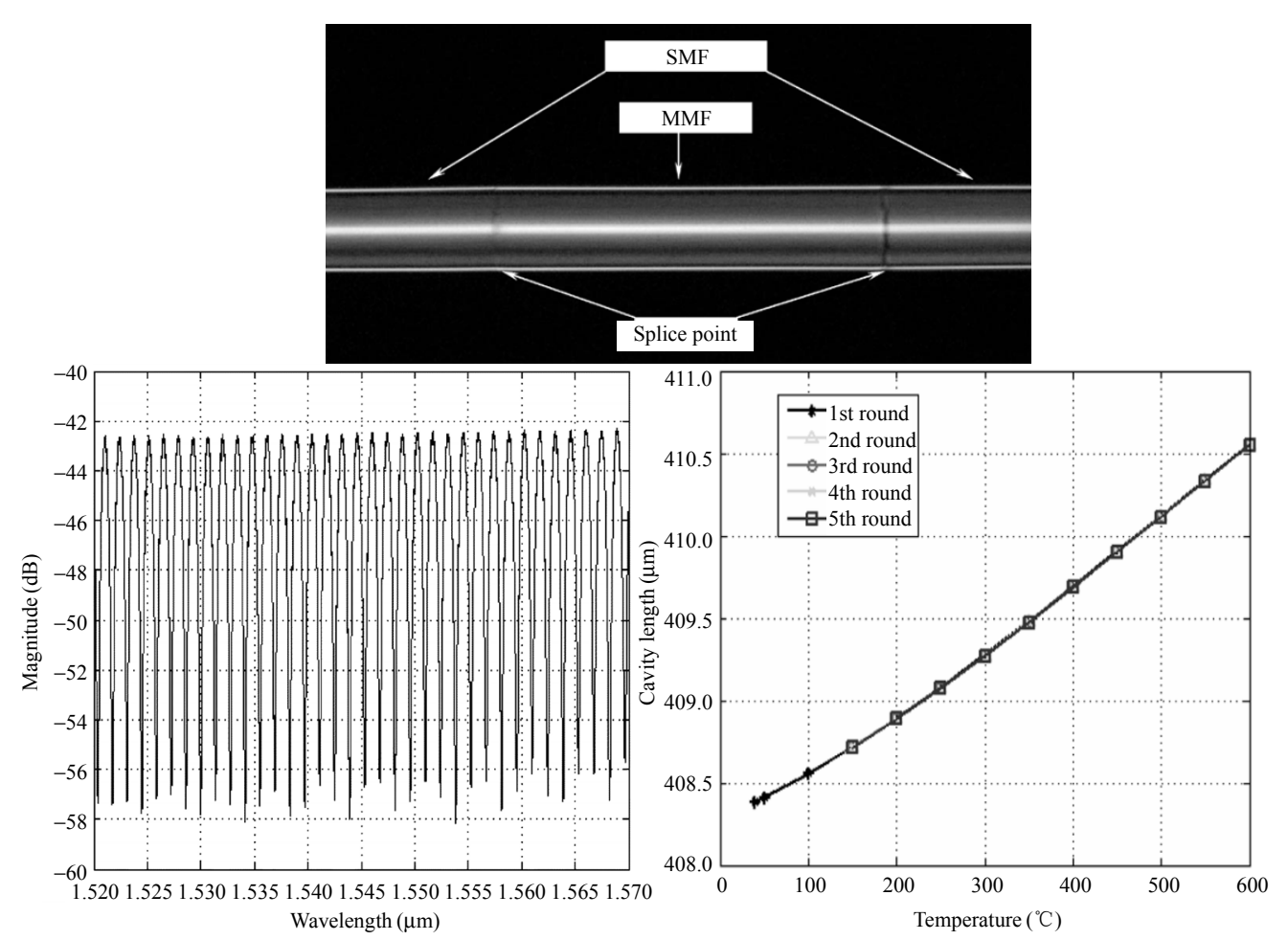

Fig. 13 Picture of SMS IFPI sensor and its spectra and temperature response [105].

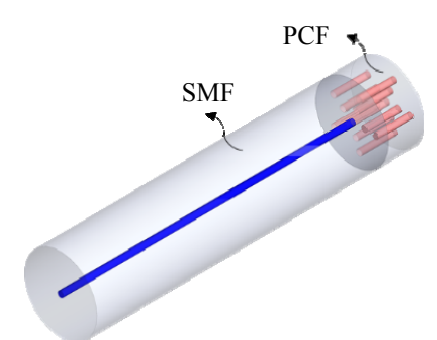

Fig. 14 Schematic diagram of tip-type IFPI formed by splicing an SMF and a PCF.

\subsection{Typical EFPI Structures}

Although the IFPI structure has the advantages of high mechanical performance and easy fabrication, two drawbacks limit its applications. One is the cross sensitivity to temperature, which makes the test of all the other parameters not accurate when there are evident temperature variations. The other is the fact that there is not access for biochemical samples to go into the FP cavity. Thus, the IFPI sensors can only use the end surface to perform the biochemical sensing. The EFPI structures are often sandwiched with an air cavity between two reflective surfaces. The air cavity is important to reduce temperature sensitivity, or even to make temperature-insensitive sensors. The EFPI structure is numerous and it can be roughly divided into three categories: sandwich-shaped, diaphragm-type, and inline-type EFPI structures. Their configuration, fabrication, and applications are described as follows.

\subsubsection{Sandwich-shaped EFPIs}

The most commonly EFPI configuration is sandwich-shaped EFPI (S-EFPI), which is composed of two segment fibers with a capillary or a special fiber with air core between them. This structure can be finely classified into fiber-capillary-fiber and all-fiber structures, as shown in Figs. 15(a) and 15(b), respectively.
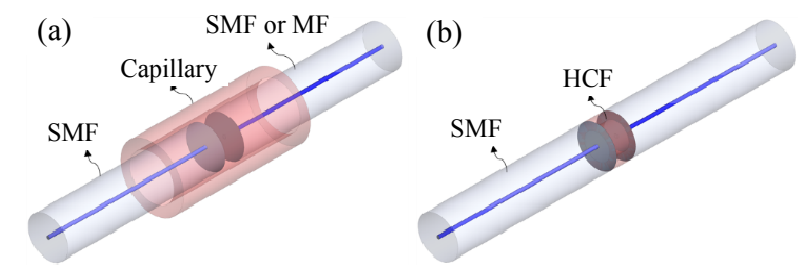

Fig. 15 Schematic diagrams of sandwich-type EFPI structure: (a) capillary-based and (b) all-fiber-based. 
For S-EFPI based on the capillary structure [110], it is obtained by aligning the two cleaved fiber end faces by using a glass capillary, and the combination between the fiber and capillary often uses the $\mathrm{CO}_{2}$ laser welting technology, oxyhydrogen flame welding method, and epoxy adhesive method. The far end of the pigtail fiber is often shattered for reducing the influence of tail reflections. Besides, it also can be coated with a highly reflective film on the two reflective surfaces for acquiring much narrower linewidth of resonant peaks [111]. This kind of simple EFPI structure based on the capillary has been widely used, especially for high-pressure sensing since the silica capillary with a large thickness can withstand the high pressure.

For S-EFPI based on the all-fiber type, it is formed by twice fusion splicing a special fiber and two-segment fiber, respectively. The special fiber with air core can be suspended core fiber (SCF) [112], photonic crystal fiber (PCF) with an air cavity [113], hollow-core fiber (HCF) [114], and small silica rod [115], etc. The fabrication process of the S-EFPI based on the all-fiber type is largely simplified by splicing a section of a special fiber with air core between two segment cleaved fibers. However, its fabrication has the disadvantages of difficulty to precisely control the length of the special fiber, namely the FP cavity length, and needing manual alignment during the fusion splicing between the SMF and the special fiber. Besides, this structure is all-fiber and can be applied in high temperature environment, and the pigtail fiber can also be a fiber with air micro-channel for achieving gas sensing or RI detection.

\subsubsection{Diaphragm-type EFPIs}

Another classic EFPI configuration is diaphragm-type EFPI (D-EFPI), whose diaphragm is positioned by a cleaved or polished end fiber. According to the functions of the diaphragm, the D-EFPI can be finely classified into two types, as shown in Fig. 16. Their detailed description is as follows.

For the diaphragm only acting as a second surface, the D-EFPI structure is almost similar to the S-EFPI structure, but the pigtail fiber is replaced by a diaphragm, as shown in Fig. 16(a). Figures 16(a1) and 16(a2) show the D-EFPI structures based on the capillary and all-fiber, respectively. The diaphragm can be an optical fiber with a length of only a few tens of microns, or a reflective film. For example, Donlagic et al. [116] proposed a miniature fiber FP pressure sensor based on the $\mathrm{SIO}_{2}$ diaphragm. Besides, the etched MMF can be replaced by a section of HCF. Another D-EFPI structure is based on a fused silica ferrule with a V-shaped hole at end [117]. A cleaved SMF is inserted into the silica ferrule, and a fusion silica diaphragm is attached to the silica ferrule by heating fusion bonding. This structure can enhance the pressure sensitivity as it introduces a large effective diameter of the diaphragm. The D-EFPI structure with a diaphragm acting as a second reflective surface is often applied for pressure, ultrasound, RI, humidity, and immune sensing. As a pressure or ultrasound sensor, the thickness of the diaphragm is often optimized for the pressure detection with a certain range. The material of the diaphragm can be fusion silica [117], copper [118], polymer [119], and so on. Besides, this structure can also be used as RI, gas, bio-sensors when the diaphragm is a sensitive film, such as chitosan [120] and graphene [121].

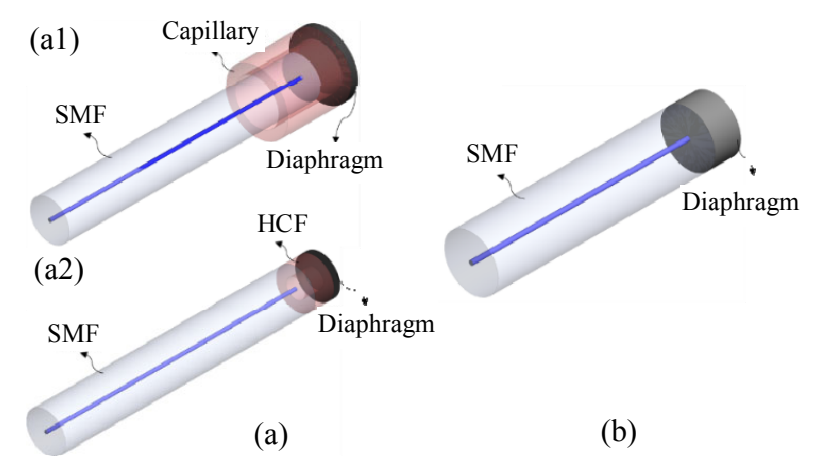

Fig. 16 Schematic diagrams of the D-EFPI structure when the diaphragm functions as (a) the second reflective surface and (b) FP cavity. 
For the diaphragm as an FP cavity, the D-EFPI structure is only composed of an SMF and a diaphragm at the end of the $\operatorname{SMF}[122,123]$, as shown in Fig. 17. The FP cavity is formed owing to the RI difference at the fiber-diaphragm interface and the diaphragm-air interface. The diaphragm can be formed by a single material or different materials with multilayer. The fabrication process of this structure is cleaving and then coating, and the coating method can be used with ionic self-assembly monolayer, Langmuir-Blodgett technique, and so on. In this structure, due to the fact that the diaphragm can be formed by kinds of sensitive films, it is mainly used to ultrasound, humidity, gas, and temperature sensing.

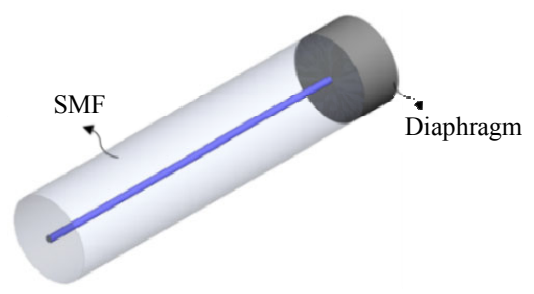

Fig. 17 Schematic diagrams of diaphragm-type EFPI structure when the diaphragm is functioned as an FP cavity.

\subsubsection{Inline-type EFPIs}

Another classic EFPI configuration is inline EFPI (I-EFPI), whose fabrication is used by state-of-the-art micromachining techniques including excimer laser micromachining, femtosecond laser micromachining, and FIB milling. These technologies make available EFPI with small size, high stability, and good product repeatability. The I-EFPI structure can be categorized into semi-open I-EFPI and sealed I-EFPI, as shown in Figs. 18(a) and 18(b), respectively.

For semi-open I-EFPI, the FP cavity is semi-open, which is made in the side of a miniaturized fiber by using fs laser micromachining or FIB milling without splicing. Rao et al. [15] fabricated EFPI structures in both the SMF and PCF by the fs laser micromachining. Wei et al. [124] further enhanced the performance of the semi-open
EFPI by using a coherent fs laser and also monitoring the interference of the fabricated device in real time, as shown in Fig. 19. The fringe visibility of the fabricated device was enhanced up to $14 \mathrm{~dB}$ and was used for high-temperature sensing of up to $1000^{\circ} \mathrm{C}$. However, after ablation by the fs laser, its mechanical strength was not as good as that of the fiber before the ablation. This semi-open FP cavity structure can make use of a Fresnel reflection to form a hybrid FP structures.

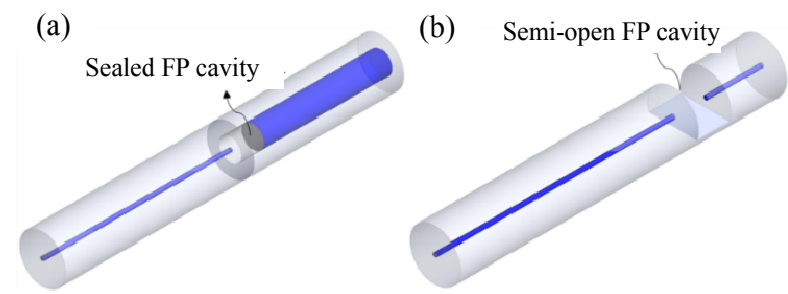

Fig. 18 Schematic diagrams of the inline EPI structure with (a) sealed and (b) semi-open FP cavity.

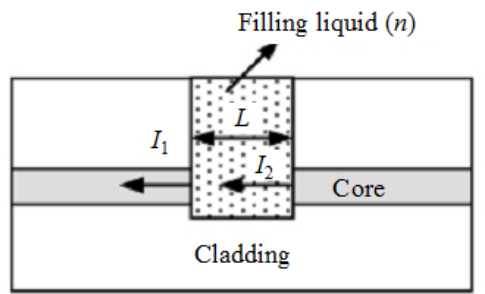

(a)

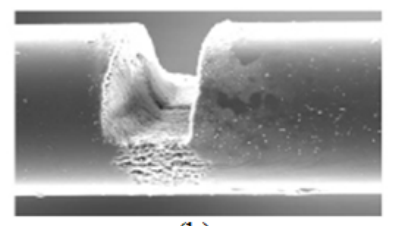

(b)

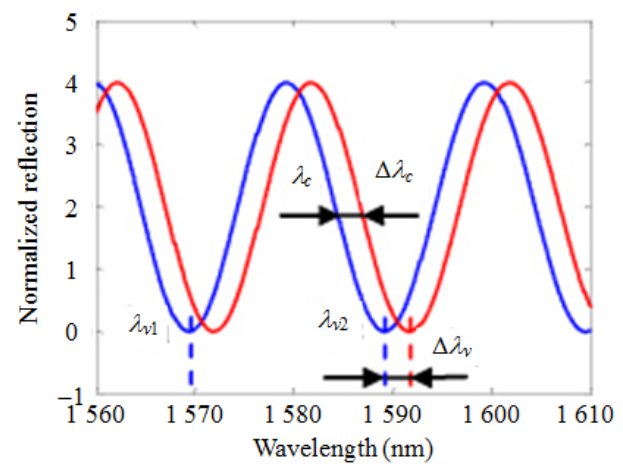

(c)

Fig. 19 Fiber inline FPI fabricated by fs laser micromachining: (a) structural schematic, (b) SEM image, and (c) simulated interference spectrum. 
For sealed I-EFPI, it is formed by splicing a fiber with a micro-hole and a cleaved fiber $[5,6$, 125]. Its fabrication process mainly has two steps. Firstly, micromachining a groove end face on a cleaved fiber, and then splicing the fiber with a groove end face and a cleaved fiber with a flat surface. The length and structure of the FP cavity can be adjusted by the groove deep and the splicing parameters. The micro-hole can be fabricated by chemical etching, fs laser inscription, and laser inscription. For the chemical etching method, the hydrofluoric (HF) acid, sometimes buffered HF acid (HF mixed with $\mathrm{NH}_{4} \mathrm{~F}$ ), is often used for the etching. Gong et al. [125] proposed an I-EFPI sensors fabricated by chemical etching Er-doped fiber with mixed hydrochloric $(\mathrm{HCl})$ and $\mathrm{HF}$ acid. The sensor performance was greatly improved by the chemical reaction between $\mathrm{HCl}$ acid and doperd $\mathrm{Er}_{2} \mathrm{O}_{3}$. This kind of sensor is insensitive to temperature while highly sensitive to strain, with sensitivities of $0.65 \mathrm{pm} /{ }^{\circ} \mathrm{C}$ and $3.15 \mathrm{pm} / \mu \varepsilon$, respectively. The main advantage of chemically etched EFPIs is the simple and low-cost fabrication process. However, the final sensing performance is strongly dependent on the fusion splicing process and the chemically etched surface is cone-shaped, which is not preferred for high-quality EFPIs. For fs laser micromachining, very low heat effect during fabrication is a big advantage. For UV laser micromachining, Ran et al. [126, 127] used a $157 \mathrm{~nm}$ excimer laser micromachining system to fabricate kinds of tip-tip EFPIs for pressure and RI sensing. One of the EFPI tip sensor with a sealed air cavity for high-resolution RI measurement offered a RI resolution of $4 \times 10^{-5}$ in its linear operating range, as shown in Fig. 20. In addition, this group [128] proposed a miniature inline fiber-optic FP strain sensor on a PCF, and it achieved precise strain measurement at high temperature of up to $800{ }^{\circ} \mathrm{C}$.

The sensing characteristics of different FP-based FOM sensors are compared in Table 5.

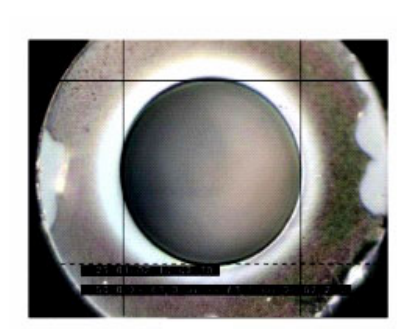

(a)

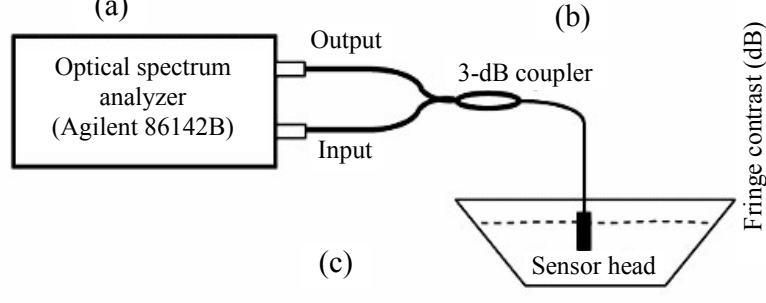

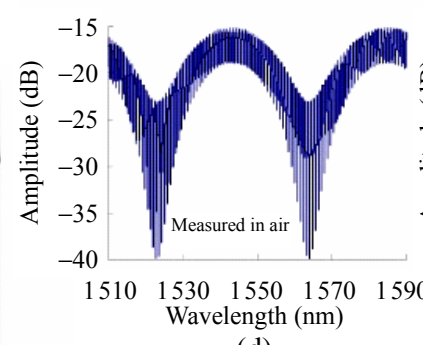

(d)

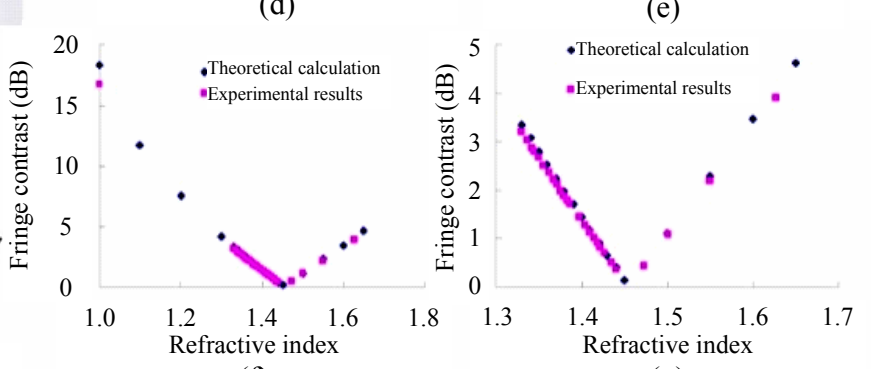

(f)

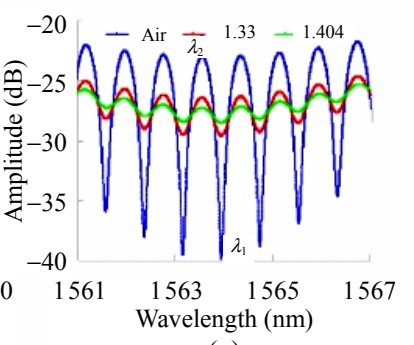

(e)

(g)

Fig. 20 Microscopic image and experimental setup of the FP sensor based on the micromachined hole introduced on the fiber cross section and its RI response. 
Table 5 Sensing characteristics comparison of different FP-based FOM sensors.

\begin{tabular}{|c|c|c|c|}
\hline Type & Structure & Main sensing characteristics & Ref. \\
\hline \multirow[t]{9}{*}{ IFPI } & Formed by broadband FBG mirrors & Temperature resolution: $0.005{ }^{\circ} \mathrm{C}$ in the range of $25{ }^{\circ} \mathrm{C}-170{ }^{\circ} \mathrm{C}$ & [129] \\
\hline & Formed by two FBGs & Strain sensitivity: $40 \mathrm{pm} / \mu \varepsilon$ & [130] \\
\hline & Formed by a reflective in-fiber metallic & Temperature measuring up to $1100{ }^{\circ} \mathrm{C}$ & [83] \\
\hline & splice and an optical fiber end & Temperature resolution: $<4{ }^{\circ} \mathrm{C}$ & \\
\hline & SMF & Resistant temperature: up to $800{ }^{\circ} \mathrm{C}$ & \\
\hline & Splicing a TCF and an SMF & RI sensitivity: $240 \mathrm{~dB} / \mathrm{RIU}$ in the range of $1.3326-1.4305$ & [107] \\
\hline & & RI sensitivity: $1110.7 \mathrm{~dB} / \mathrm{RIU}$ at the RI of 1.4305 & \\
\hline & SMF-MMF-SMF & $\begin{array}{l}\text { Strain repeatability and resolution: } \pm 0.20 \% \text { and } 0.20 \% \text { respectively in the } \\
\text { range of } 0-400 \mu \varepsilon\end{array}$ & [105] \\
\hline & & $\begin{array}{l}\text { Temperature repeatability and resolution: } \pm 0.15 \% \text { and } 0.037 \% \text { respectively in } \\
\text { the range of room temperature }-600{ }^{\circ} \mathrm{C}\end{array}$ & \\
\hline \multirow{9}{*}{$\begin{array}{l}\text { Sandwich-shaped } \\
\text { EFPI }\end{array}$} & SMF-TCF-SMF & Temperature sensitivity: $18.3 \mathrm{pm} /{ }^{\circ} \mathrm{C}$ & [132] \\
\hline & & Operating temperature: up to $850^{\circ} \mathrm{C}$ & \\
\hline & SMF-etched MMF-SiO 2 diaphragm & Pressure response: $1.1 \mathrm{rad} / 40 \mathrm{kPa}$ at $1550 \mathrm{~nm}$ & [116] \\
\hline & & Pressure resolution: $300 \mathrm{~Pa}$ & \\
\hline & SMF-a offset silica rod-SMF & $\begin{array}{l}\text { Pressure sensitivities of carbon dioxide, nitrogen, and oxygen gas: } \\
6.2 \mathrm{~nm} / \mathrm{MPa}, 4.1 \mathrm{~nm} / \mathrm{MPa} \text {, and } 3.6 \mathrm{~nm} / \mathrm{MPa} \text {, respectively }\end{array}$ & [115] \\
\hline & & RI sensitivity: $1526 \mathrm{~nm} / \mathrm{RIU}$ & \\
\hline & & Temperature sensitivity: $-14 \mathrm{pm} /{ }^{\circ} \mathrm{C}$ & \\
\hline & A silica capillary assembly & Pressure sensitivity: $241 \mathrm{~nm} / \mathrm{MPa}$ & [133] \\
\hline & & Resolution and repeatability: $0.0004 \mathrm{MPa}$ and $0.05 \% \mathrm{FS}$, respectively & \\
\hline \multirow[t]{8}{*}{ Diaphragm-type EFPI } & A copper diaphragm & Pressure sensitivity: $1.6 \mathrm{rad} / \mathrm{bar}$ in the range of $0-600 \mathrm{kPa}$ & [118] \\
\hline & An ultra-thin silver diaphragm & Pressure sensitivity: $1.6 \mathrm{~nm} / \mathrm{kPa}$ & [134] \\
\hline & & Resonant frequency: $1.44 \mathrm{MHz}$ & \\
\hline & A thin graphene film & Pressure sensitivity: $39.4 \mathrm{~nm} / \mathrm{kPa}$ & [135] \\
\hline & Formed by a fused silica ferrule and a fused & Pressure sensitivity: $2.93 \mathrm{~nm} / \mathrm{psi}$ & [136] \\
\hline & silica diaphragm & Pressure reolution:0.01 psi & \\
\hline & & Operating temperature: up to $700{ }^{\circ} \mathrm{C}$ & \\
\hline & & Temperature sensitivity: $0.0076 \mathrm{psi} /{ }^{\circ} \mathrm{C}$ & \\
\hline \multirow[t]{9}{*}{ Inline-type EFPI } & An in-fiber rectangular air bubble & Strain sensitivity: $43.0 \mathrm{pm} / \mu \varepsilon$ & [137] \\
\hline & & Temperature sensitivity: $2.0 \mathrm{pm} /{ }^{\circ} \mathrm{C}$ & \\
\hline & & Temperature strain-sensitivity: $0.046 \mu \varepsilon /{ }^{\circ} \mathrm{C}$ & \\
\hline & All-fiber EFPI with long-active-length & Strain-measuring: up to $3000 \mu \varepsilon$ & [138] \\
\hline & & Strain-resolution: $0.5 \mu \varepsilon$ at $1 \mathrm{kHz}$ & \\
\hline & & Temperature strain-sensitivity: $0.055 \mu \varepsilon /{ }^{\circ} \mathrm{C}$ & \\
\hline & An microcavity & Pressure sensitivity: $0.01 \mathrm{rad} / \mathrm{MPa}$ in the range of $0-60 \mathrm{MPa}$ & [127] \\
\hline & An open micro-notch cavity & RI sensitivity: $1163 \mathrm{~nm} / \mathrm{RIU}$ & [124] \\
\hline & & Temperature cross-sensitivity: $1.1 \times 10^{-6} \mathrm{RIU} /{ }^{\circ} \mathrm{C}$ & \\
\hline
\end{tabular}




\section{4. $M Z I$ sensors}

The optical fiber MZIs have attracted significant research attentions due to their high sensitivity, compact size, and so on. The MZI structure has two independent arms, which are the reference arm and the sensing arm. The light is split into the two arms and then recombined to form the interference component according to the optical path difference (OPD) between the two arms. Particularly, the two split beams will only travel through two strictly separated paths of an MZI. Therefore, it does not have a fiber end mirror and the sensors based on the MZI structure are only transmitted type. The MZI structure is numerous, which can be classified into two types: mode field mismatch and air hole based MZIs, as described below.

\subsection{MZIs based on mode field mismatch}

The definition of the mode field mismatch based MZI structure is similar to that of the intrinsic FPI whose material of transmitted waveguide is fiber-self. The traditional MZI structure realizes the function of dividing light into two separated paths by couplers, but now the coupler has been rapidly replaced with inline waveguide interferometers in the fiber MZI structures, such as LPFG, core mismatch type, small air-hole, offset splicing, and fiber tapering. As shown in Fig. 20(a) [139], a part of the beam guided as the core mode of an SMF is coupled to cladding modes of the same fiber by an LPFG and then re-coupled to the core mode by another LPFG. Lim et al. [140] developed an all-fiber MZI by mechanically inducing an LPFG pair in a PCF. The interference fringe of the MZI formed by the LPFG pair varied with the period and the strength of the gratings. In order to improve the RI sensitivity, the method of fiber tapering had been applied to the separated region between two LPFGs. Its RI sensitivity was about five times higher than that of a normal LPG pair [139].

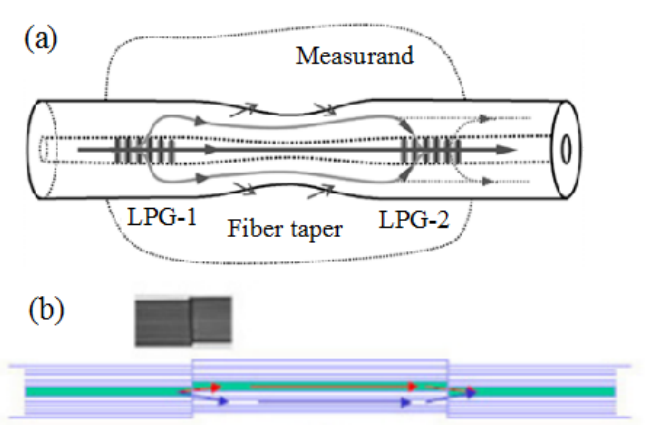

(1)

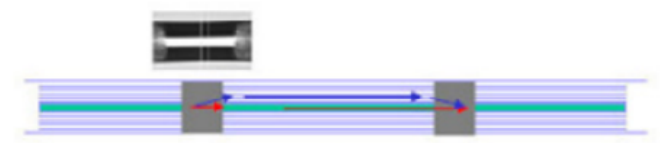

(2)

(c)

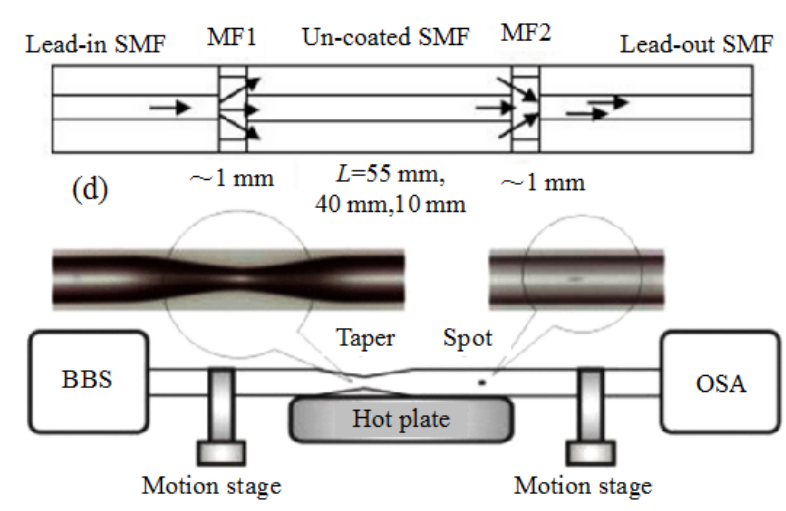

Fig. 21 Schematic diagrams of the mode field mismatch based MZI formed by (a) LPFG [139], (b) offset splicing [141], (c) core-mismatching [142], and (d) taper fiber [143].

Splicing two fibers with a minute lateral offset is another way to achieve a beam into the core and the cladding modes of a fiber, as shown in Fig. 21(b). Hea et al. [141] proposed an all-PCF MZI formed by fusion splicing two pieces of a PCF with a small lateral offset. This structure was observed that the interference fringe shifted linearly toward the shorter wavelength direction with a sensitivity of $\sim 2.2 \mathrm{pm} / \mu \varepsilon$ and a good performance up to over $1500{ }^{\circ} \mathrm{C}$ was expected. Besides, collapsing air holes of a PCF is another good way of making an inline MZI. It is easy and does not need any troublesome cleaving or aligning process.

Another method for splitting the beam in a fiber is to use the fibers with different core diameters, as shown in Fig. 21(c). For example, Nguyen et al. 
[142] proposed a temperature sensor formed by splicing a section of the uncoated SMF with two short sections of the MMF whose core was composed of pure silica. In this sensor, the light propagating through the core of the SMF was spread at the MMF region and then coupled into the core and cladding of the next SMF. The temperature sensor could measure temperature stably up to more than $900{ }^{\circ} \mathrm{C}$ with a sensitivity of $0.088 \mathrm{~nm} /{ }^{\circ} \mathrm{C}$. Figure 21(d) [143] shows an effective inline MZI structure by tapering a fiber along with a small air core or spot. Due to the tapering, the core mode diameter was increased so that a part of it could be coupled to cladding modes and then recoupled by a small air or spot. It is cost effective and relatively simple but mechanically weak, especially at the tapering region.

\subsection{MZIs based on air hole}

One of the simplest principles of the MZI is just achieved by partially ablating fiber cladding and fiber core using fs laser. This structure is composed of a trench exposed to the environment, as shown in Fig. 22. From the structure diagram, one of two light transmission paths is the trapezoidal cavity in the trench and the other is the rest of the fiber core. Zhao et al. [144] proposed an easy-to-fabricate simple sensing structure with a trench and partially ablated fiber core fabricated by using an $800 \mathrm{~nm}, 35$ $\mathrm{fs}$, and $1 \mathrm{kHz}$ laser, whose RI and temperature sensitivities were about $10^{4} \mathrm{~nm} / \mathrm{RIU}$ and $51.5 \mathrm{pm} /{ }^{\circ} \mathrm{C}$ at $200{ }^{\circ} \mathrm{C}-875^{\circ} \mathrm{C}$. This MZI structure is of very high fabrication and sensing repeatability. The MZI based on a trench can also be coated with the high RI film or a biological film for specific molecules label-free sensing. For example, Wang et al. [7] proposed a fs laser fabricated by fiber inline micro MZI with deposited palladium (Pd) film for hydrogen sensing. The transmission spectrum of the sensor depended on the microcavity length and the wavelength shift was induced by the RI change of the Pd film. However, the RI sensitivity for hydrogen concentration detection was not given.
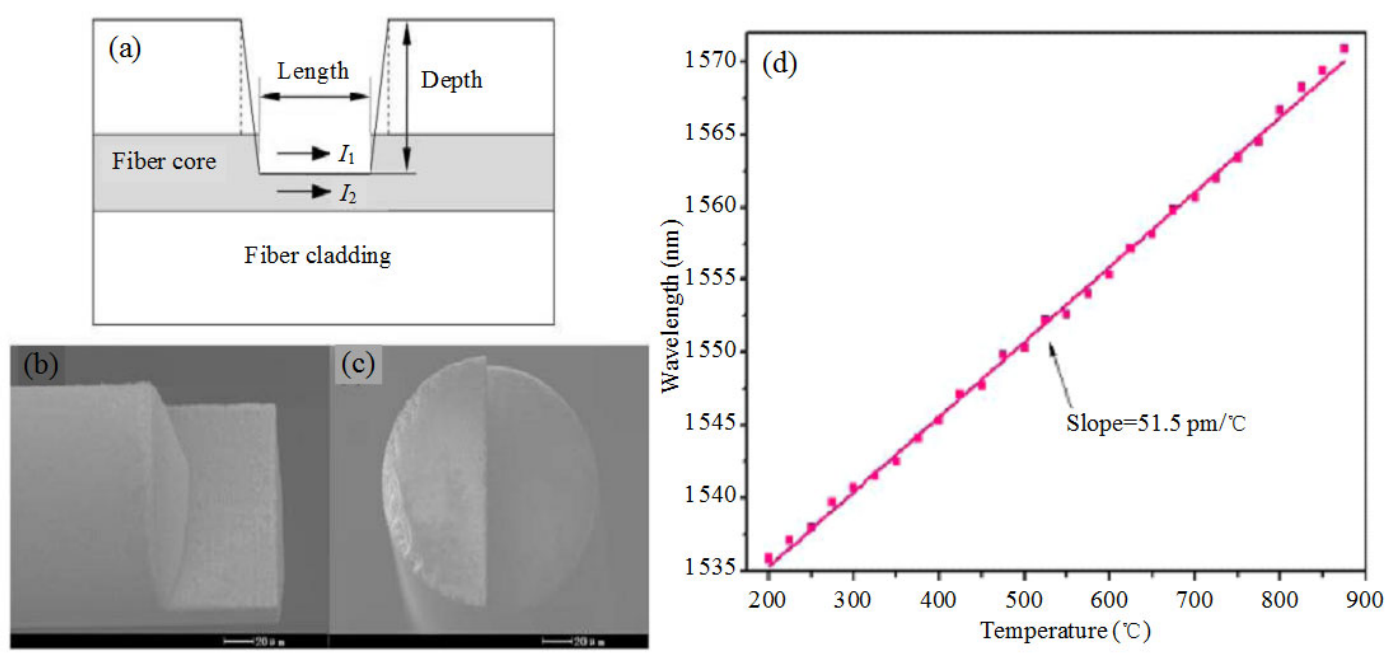

Fig. 22 Schematic diagrams of MZI based on a air hole fabricated by fs laser pulses and its temperature response [144].

Another MZI structure based on one air hole is combined with the sealed air hole in fiber, as shown in Fig. 23. Its fabrication process is similar to that of the EFPI structure based on the sealed cavity. If the size of the sealed air cavity is much larger than that of the fiber core, this structure can be an RI sensor 
due to exciting high-order cladding modes deliberately. For example, Gong et al. [145] proposed a fiber inline MZI based on a hollow ellipsoid and the RI, curvature, and temperature sensitivities were $-14.3 \mathrm{~dB} / \mathrm{RIU},-0.61 \mathrm{~dB} / \mathrm{m}^{-1}$, and $19.4 \mathrm{pm} /{ }^{\circ} \mathrm{C}$, respectively. In addition, fabricating a microchannel in the air cavity is another way to achieve RI sensing. Li et al. [146] proposed an innovative label-free optical fiber biosensor based on an MZI for bovine serum albumin (BSA) concentration detection. The proposed fiber biosensor utilized a micro-cavity with microfluidic channels to induce MZI fabricated by means of femtosecond laser micromachining and chemical etching. A fiber interferometer of this type exhibited an ultrahigh RI sensitivity of $-10055 \mathrm{~nm} / \mathrm{RIU}$ and a detection limit of $3.5 \times 10^{-5}$ RIU. Besides an air cavity in the fiber, there can be two air cavities embedded in the optical fiber [147]. The optical fiber with two air cavities and core-cladding boundary constitute two different light paths. When traveling through the first air cavity, some cladding modes are excited, parts of which are coupled back to the core mode after travelling distance $L$. For improving sensitivity, the MZI based on the air cavity and the microchannel can combine with an optical taper. Reference [148] showed that the core mode was coupled to higher-order cladding modes when there existed a single taper to make the optical fiber narrows.

The sensing characteristics of different MZI-based FOM sensors are compared in Table 6.
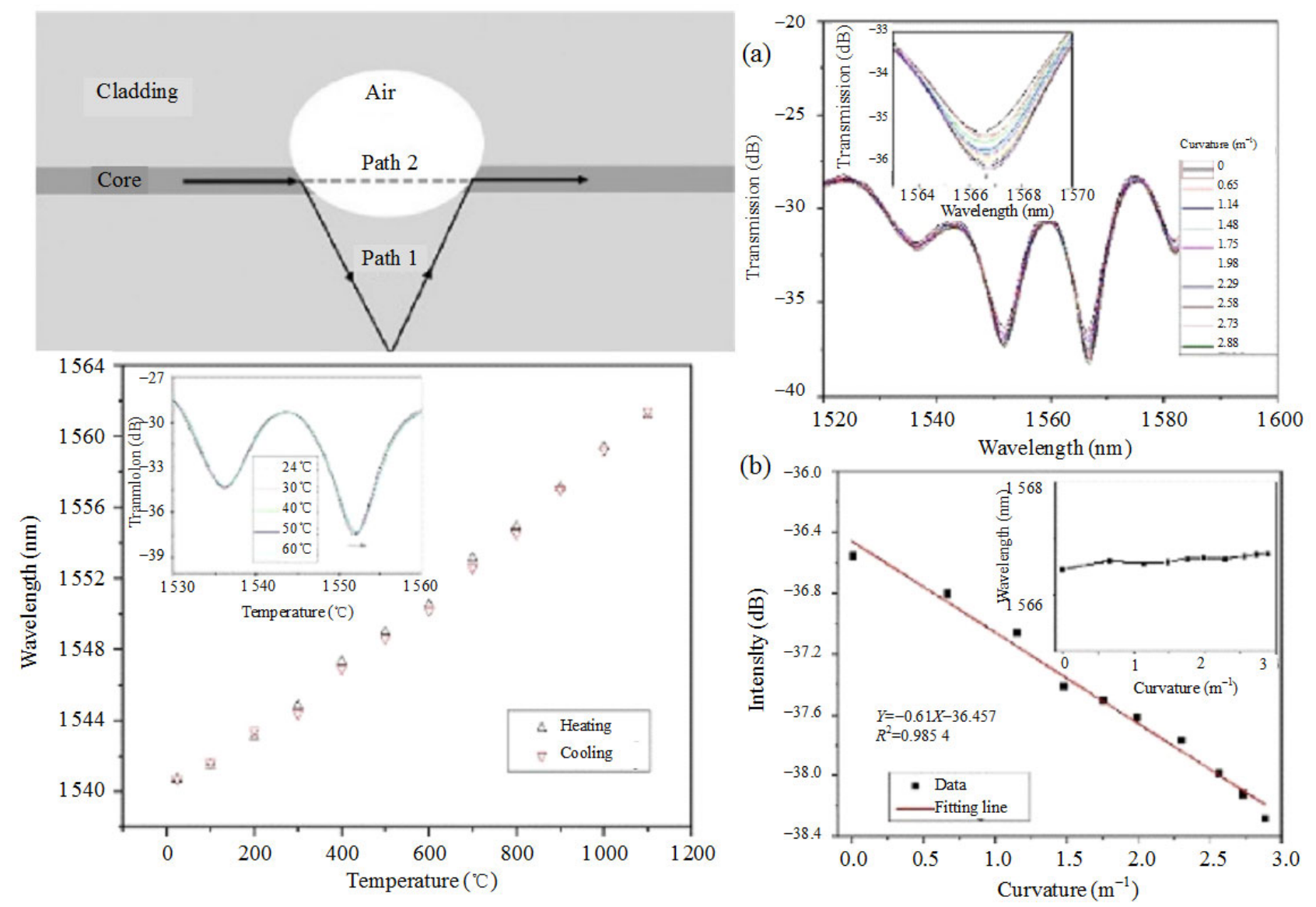

Fig. 23 Schematic diagrams of the fiber MZI based on a sealed air hole and its temperature, RI, and curvature response [145]. 
Table 6 Sensing characteristics comparison of different MZI-based FOM sensors.

\begin{tabular}{|c|c|c|c|}
\hline Type & Structure & Main sensing characteristics & Ref. \\
\hline \multirow{24}{*}{$\begin{array}{l}\text { MZI based on mode } \\
\text { field mismatch }\end{array}$} & SMF-FMF-SMF & Temperature sensitivity: $48.2 \mathrm{pm} /{ }^{\circ} \mathrm{C}$ with temperature up to $1000{ }^{\circ} \mathrm{C}$ & [149] \\
\hline & SMF-MMF-thinned fiber-SMF & Strain sensitivity: $-2.99 \mathrm{pm} / \mu \varepsilon$ & [150] \\
\hline & & RI sensitivity: $-25.2935 \mathrm{~nm} / \mathrm{RIU}$ & \\
\hline & SMF-PCF-SMF & Strain sensitivity: $2.1 \mathrm{pm} / \mu \varepsilon$ & [151] \\
\hline & & Temperature sensitivity: $13.24 \mathrm{pm} /{ }^{\circ} \mathrm{C}$ & \\
\hline & SMF-misaligned TCF-SMF & Strain sensitivity: $-0.023 \mathrm{~dB} / \mu \varepsilon$ & [152] \\
\hline & & Temperature sensitivity: $51 \mathrm{pm} /{ }^{\circ} \mathrm{C}$ & \\
\hline & SMF-TCF-SMF-TCF-SMF & RI sensitivity: $159 \mathrm{~nm} / \mathrm{RIU}$ & [153] \\
\hline & tapered SMF-PCF-tapered SMF & RI sensitivity: $260.8 \mathrm{~nm} / \mathrm{RIU}$ & [154] \\
\hline & SMF-MMF-SMF-MMF-SMF & Curvature sensitivities: $(-14.40 \pm 0.02) \mathrm{nm} / \mathrm{m}^{-1}$ & [155] \\
\hline & SMF-tapered HCF-SMFs. & Curvature sensitivities: $-10.9041 \mathrm{~dB} / \mathrm{m}^{-1}$ & [156] \\
\hline & & Curvature resolution: $0.000917 \mathrm{~m}^{-1}$ & \\
\hline & SMF-MMF-dispersion compensation fiber-MMF-SMF & $\begin{array}{l}\text { Curvature sensitivities: }-12.82 \mathrm{~nm} / \mathrm{m}^{-1} \text { and }-14.42 \mathrm{~nm} / \mathrm{m}^{-1} \text { for two } \\
\text { resonant dips }\end{array}$ & [157] \\
\hline & On one tapered SMF & RI sensitivity: $-26.087 \mathrm{~nm} / \mathrm{RIU}$ & [158] \\
\hline & & Temperature sensitivity: $0.071 \mathrm{~nm} /{ }^{\circ} \mathrm{C}$ & \\
\hline & On an inline abrupt taper structure & Strain sensitivity: $2000 \mathrm{~nm} / \varepsilon$ & [159] \\
\hline & On concatenating two tapered SMFs & RI sensitivity: $17.1 \mathrm{~nm} / \mathrm{RIU}$ & [160] \\
\hline & MZI formed by cascaded two SMF tapers & RI sensitivity: $158.4 \mathrm{~nm} / \mathrm{RIU}$ & [161] \\
\hline & & Measuring resolution: $6.3 \times 10^{-6}$ & \\
\hline & $\begin{array}{l}\text { Based on SMF with large lateral offset fusion } \\
\text { splicing }\end{array}$ & RI sensitivity: higher than $3402 \mathrm{~nm} / \mathrm{RIU}$ in the range of $1.0-1.0022$ & [162] \\
\hline & $\begin{array}{l}\text { Formed by an LPFG pair with a fiber-taper section } \\
\text { in between }\end{array}$ & RI sensitivity: five times higher than that of a normal LPG pair & [139] \\
\hline & MZI based on suspended twin-core fiber & $\begin{array}{l}\text { Curvature sensitivities: } 2.22 \mathrm{~nm} / \mathrm{m}^{-1} \text { ( } x \text {-polarization) and }-2.56 \mathrm{~nm} / \mathrm{m}^{-1} \\
\text { (y-polarization) }\end{array}$ & [163] \\
\hline & & Measuring resolution: $\pm 0.01 \mathrm{~m}^{-1}$ & \\
\hline & On PCF & Curvature sensitivities: $3.046 \mathrm{~nm} / \mathrm{m}^{-1}$ & [164] \\
\hline \multirow{8}{*}{ MZI based on air hole } & & Temperature sensitivity: $0.0019 \mathrm{~nm} /{ }^{\circ} \mathrm{C}$ & \\
\hline & On a microfiber with an inner air cavity & Strain sensitivity: $6.8 \mathrm{pm} / \mu \varepsilon$ & [165] \\
\hline & On SMF with an open microcavity & $\begin{array}{l}\text { Temperature sensitivity: } 0.046 \mathrm{~nm} /{ }^{\circ} \mathrm{C} \text { in the range of } 100{ }^{\circ} \mathrm{C}- \\
1100{ }^{\circ} \mathrm{C}\end{array}$ & [166] \\
\hline & On an open microcavity & RI sensitivity: $-9370 \mathrm{~nm} / \mathrm{RIU}$ & [167] \\
\hline & $\begin{array}{l}\text { On dual internal mirrors formed by a hollow sphere } \\
\text { pair }\end{array}$ & Strain sensitivity: $-1.44 \mathrm{pm} / \mu \varepsilon$ & [147] \\
\hline & On two microcavities & $\begin{array}{l}\text { Temperature sensitivity: } 109 \mathrm{pm} /{ }^{\circ} \mathrm{C} \text { in the range of } 500{ }^{\circ} \mathrm{C}- \\
1200{ }^{\circ} \mathrm{C}\end{array}$ & [168] \\
\hline & Tapered MZI based on two inner air cavities & Temperature sensitivity: $28.7 \mathrm{pm} /{ }^{\circ} \mathrm{C}$ & [148] \\
\hline & & RI sensitivity: $464.96 \mathrm{~nm} / \mathrm{RIU}$ & \\
\hline
\end{tabular}

\section{MI sensors}

Fiber-optic sensors based on MIs are quite similar to MZIs. The basic concept is the interference between the beams in two arms, but each beam is reflected at the end of each arm in an MI. The fabrication method and the operation principle of MIs are almost the same as MZIs, and their main difference is the existence of the reflector(s). According to the fabrication technology, the structures of the MI can be classified into two types: based on with splicing and without splicing.

\subsection{MIs fabricated without splicing}

One of the MI structure without splicing is based on an LPG, as shown in Fig. 24. A part of the core mode beam is coupled to the cladding modes by the 
LPG and then reflected along with the uncoupled core mode beam by the common reflector at the end of the fiber. The reflector can be a cleaved fiber surface and also a smooth surface coated with a sensitive film for biosensing [169, 170]. For example, Zhou et al. [169] proposed a high-resolution optical refractometer based on the LPG MI, and this sensor showed an RI resolution and sensitivity of $3 \times 10^{-6} \mathrm{RIU}$ and $3 \times 10^{3} \mathrm{deg} / \mathrm{RIU}$, respectively. Sandhu et al. [170] used a polymericnanoparticle composite thin-film overlays to reorganize the cladding modes within the sensing heads of the LPG MI sensor to enhance the RI sensitivity significantly. Using micromachining technology to inscribe MI structure in a fiber is a good way for forming MI without splicing. Liao et al. [171] proposed a fiber inline MI tip sensor based on open micro-cavity, which was fabricated by fs laser micromachining and the thin coating technique. This sensor exhibited a high RI sensitivity of $975 \mathrm{~nm} / \mathrm{RIU}$. Yuan et al. [172] proposed an MI temperature sensor formed by micromachining a step structure at the tip of an SMF using an fs laser, as shown in Fig. 25. This structure had a high fringe visibility of $18 \mathrm{~dB}$ and the sensing temperature of up to $1000{ }^{\circ} \mathrm{C}$. Another simple method to form MI structure is to taper an SMF.

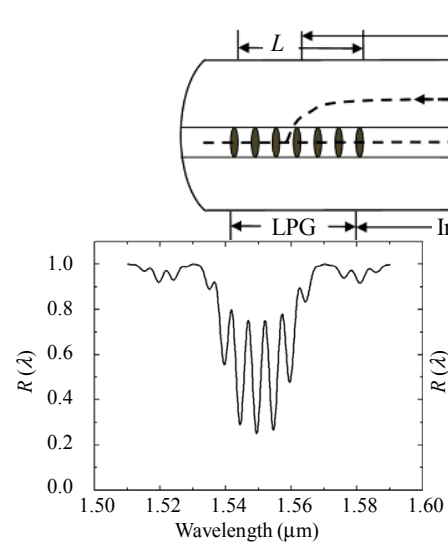

(a)

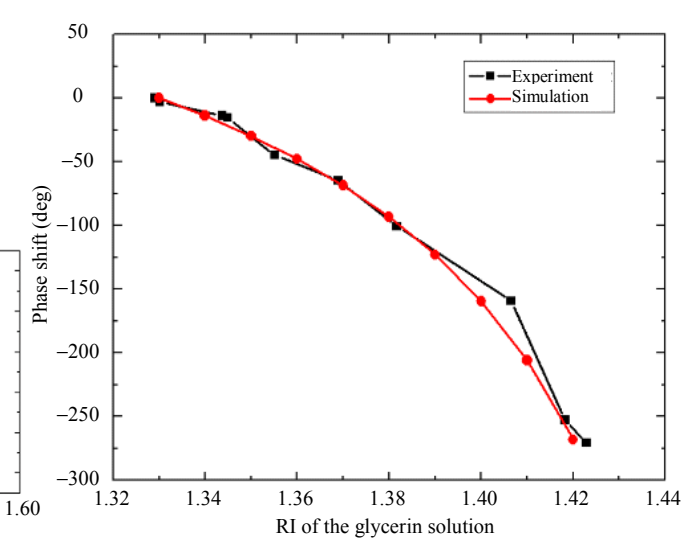

(b)

Fig. 24 Schematic diagrams of MI without splicing based on an LPFG and its spectra and RI response [169].

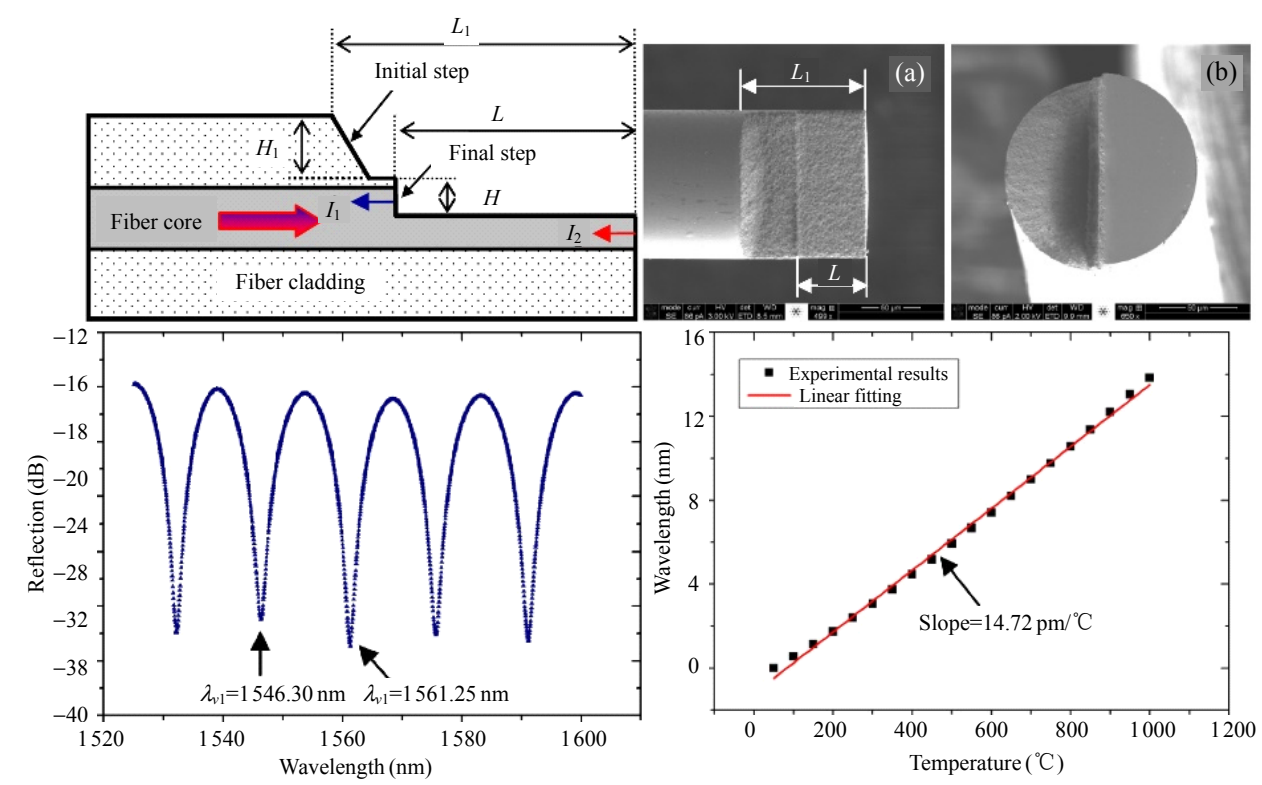

Fig. 25 Schematic diagrams of MI without splicing based on the step-structured fiber, and its spectra and temperature response [172]. 


\subsection{MIs fabricated with splicing}

The MI structures can be formed by splicing two core-mismatching fibers or offset splicing two fibers. For splicing two core-mismatching fibers, Rong et al. [173] proposed an MI liquid level sensor that consisted of a short piece of small-core-fiber (SCF) followed by an SMF tip with coating a thick silver film. The SCF excited cladding modes into the pigtail SMF through the mismatch-core splicing interface. A part of core and cladding modes was reflected back by the silver film and recoupled to fiber core through the SCF. The sensor presented a water level sensitivity of $-68.3 \mathrm{pm} / \mathrm{mm}^{-1}$. The mismatch-core fiber can be a TCF [174], MMF [10, 175] or a prefusion-inducing micro-bend SMF [176]. In order to achieve biosensing, the tip of sensor can be coated with the sensitive film. Wang et al. [177] proposed an RI sensor based on an MI with a TCF coated by carbon nanotube. This sensor was fabricated by the splice of a sectioned SMF on one end of TCF, and the other end was turned into a circular arc by fusion discharge. This sensor showed a maximum sensitivity and a minimum resolution of $178.88 \mathrm{~dB} / \mathrm{RIU}$ and $1.21 \times 10^{-4} \mathrm{RIU}$, respectively. The MZI structure based on mismatch-core fibers can also combine with taper structure. Yuan et al. [9] proposed an MI-based bending sensor consisting of a segment of two-core fiber with a dielectric mirror, and the two-core fiber was fused with an SMF and tapered at the splicing point. Besides, the side-polish method can be used to increase the evanescent field for RI sensing. Zhou et al. [178] proposed an asymmetrical two-core fiber based $\mathrm{MI}$ as an RI sensor. Part of the cladding of the two-core fiber over a small length was removed by chemical etching to make the effective RI of the fundamental mode of the side core sensitive to the ambient RI. The sensitivity of such an MI was $-270 \mathrm{~nm} / \mathrm{RIU}$ in the range of $1.34-1.38$. For offset splicing two fiber, Zhou et al. [179] demonstrated an RI sensor based on an optical fiber MI fabricated by splicing a section of TCF to a standard SMF with a core offset.
The MI-based RI sensor with a core offset of $8 \mu \mathrm{m}$ and a TCF length of $3 \mathrm{~mm}$ exhibited a high resolution of $4.9 \times 10^{-6} \mathrm{RIU}$ and sensitivity of $-202.46 \mathrm{~dB} / \mathrm{RIU}$.

The sensing characteristics of different MI-based FOM sensors are compared in Table 7.

\section{SI sensors}

\subsection{SI structures}

An SI consists of an optical fiber loop, along which two beams are propagating in counter directions with different polarization states. An input light is split into two directions by a fiber coupler and the two counter-propagating beams are combined again at the same coupler. Highbirefringence fiber (HBF) or polarizationmaintaining fiber (PMF) are commonly used in the SI to introduce birefringence for producing a wavelength dependent output for various measurements [190-192]. For the temperature sensing, the birefringence of stress-induced PMFs is generally more sensitive to temperature variation than that of standard PMFs. However, when the PMF is used to sense other physical parameters such as strain, bending, and pressure, the temperature effect must be minimized. In order to overcome this problem, polarization-maintaining PCFs have been introduced as the sensing fibers. Frazao et al. [182] presented a temperature-independent strain sensor based on high-birefringence PCF loop mirror. An elliptical hollow-core PBF based on SI with a strain sensitivity of $-0.81 \mathrm{pm} / \mu \varepsilon$ was presented, and the birefringence of the fiber was measured to be $3 \times 10^{-3}$. Low-birefringence fiber (LBF) was also employed in the Sagnac loop [193-195]. Gong et al. [184] demonstrated an optical fiber strain sensor by using a low-birefringence PCF-based Sagnac loop. The Sagnac loop was formed by the low-birefringence PCF of about $40 \mathrm{~cm}$, and a section of about $140 \mathrm{~mm}$ PCF was used as the strain sensing element. The strain sensitivity of this sensor was $-0.457 \mathrm{pm} / \mu \varepsilon$ within the range of $0 \mu \varepsilon-2520 \mu \varepsilon$. Furthermore, the 
SI structure can be formed by the taper fiber coupler, as shown in Fig. 26. Pu et al. [186] presented a low-loss and highly sensitive RI sensor based on a reflective tapered fiber couple, namely SI. The sensing structure was fabricated by fusing and tapering a twisted optical fiber. The achieved maximum sensitivity was $3617 \mathrm{~nm} / \mathrm{RIU}$ for measuring RI ranging from 1.33 to 1.41 .

The sensing characteristics of different SI-based FOM sensors are compared in Table 8.

Table 7 Sensing characteristics comparison of different MI-based FOM sensors.

\begin{tabular}{|c|c|c|c|}
\hline Fabrication method & Structure & Main sensing characteristics & Ref. \\
\hline \multirow[t]{8}{*}{$\begin{array}{l}\text { MI fabricated without } \\
\text { splicing }\end{array}$} & An LPG with an end-face & $\begin{array}{l}\text { Temperature sensitivity: }-2.5 \text { degrees } /{ }^{\circ} \mathrm{C} \text { and } 12.8 \text { degrees } /{ }^{\circ} \mathrm{C} \text { for } \mathrm{SMF} \\
\text { and germanium-boron co-doped fiber, respectively }\end{array}$ & [187] \\
\hline & $\begin{array}{l}\text { Formed by a polymeric-nanopartical } \\
\text { composite film and an LPG }\end{array}$ & RI resolution: $3 \times 10^{-3} \mathrm{RIU}$ & [170] \\
\hline & On a peanut-shape structure & $\begin{array}{l}\text { Temperature sensitivity: } 0.096 \mathrm{~nm} /{ }^{\circ} \mathrm{C} \text { with the temperature up to } \\
900{ }^{\circ} \mathrm{C}\end{array}$ & [188] \\
\hline & A step structure at the tip of an SMF & $\begin{array}{l}\text { Temperature sensitivity: } 14.72 \mathrm{~nm} /{ }^{\circ} \mathrm{C} \text { with the temperature up to } \\
1100{ }^{\circ} \mathrm{C}\end{array}$ & [172] \\
\hline & An abrupt fiber-taper & Temperature sensitivity: $118.6 \mathrm{pm} /{ }^{\circ} \mathrm{C}$ in the range of $500{ }^{\circ} \mathrm{C}-800{ }^{\circ} \mathrm{C}$ & [189] \\
\hline & $\begin{array}{l}\text { A single symmetrically abrupt taper SMF } \\
\text { with thick gold coating }\end{array}$ & A change of RI: 0.01 causing a wavelength shift of $0.29 \mathrm{~nm}$ & [190] \\
\hline & $\begin{array}{l}\text { An open microcavity and an Ag film } \\
\text { coating }\end{array}$ & RI sensitivity: $975 \mathrm{~nm} / \mathrm{RIU}$ at the RI of 1.484 & [171] \\
\hline & A taper SMF & Bending sensitivity: $1.13 \mathrm{rad} /$ degree & [191] \\
\hline \multirow[t]{10}{*}{ MI fabricated with splicing } & SMF-TCF & Temperature sensitivity: $0.140 \mathrm{~nm} /{ }^{\circ} \mathrm{C}$ in the range of $30{ }^{\circ} \mathrm{C}-800{ }^{\circ} \mathrm{C}$ & [192] \\
\hline & SMF-offset TCF & $\begin{array}{l}\text { RI sensitivity: }-202.46 \mathrm{~dB} / \mathrm{RIU} \\
\text { RI resolution: } 4.9 \times 10^{-6} \mathrm{RIU}\end{array}$ & [179] \\
\hline & SMF-TCF coated by carbon nanotube & $\begin{array}{l}\text { RI sensitivities for wavelength and intensity interrogations: } \\
165.77 \mathrm{~nm} / \text { RIU and } 178.88 \mathrm{~dB} / \mathrm{RIU}\end{array}$ & [177] \\
\hline & SMF-TCF-SMF & $\begin{array}{l}\text { RI sensitivities: }-208.24 \mathrm{~dB} / \mathrm{RIU} \text { and } 125.44 \mathrm{~dB} / \mathrm{RIU} \text { in the range of } \\
1.440-1.500\end{array}$ & [174] \\
\hline & $\begin{array}{l}\text { Formed by tapering the spliced region } \\
\text { between an SMF and an MCF }\end{array}$ & Temperature sensitivity: $165 \mathrm{pm} /{ }^{\circ} \mathrm{C}$ with the temperature up to $900{ }^{\circ} \mathrm{C}$ & [193] \\
\hline & $\begin{array}{l}\text { Formed by a mismatching fiber joint and } \\
\text { an end-cleaved fiber }\end{array}$ & Temperature sensitivity: $115.34 \mathrm{pm} /{ }^{\circ} \mathrm{C}$ at $550{ }^{\circ} \mathrm{C}$ & [176] \\
\hline & A core mismatched structure & Temperature sensitivity: $-0.05 \mathrm{rad} /{ }^{\circ} \mathrm{C}$ in the range of $20{ }^{\circ} \mathrm{C}-90{ }^{\circ} \mathrm{C}$ & [194] \\
\hline & A three microspheres array & RI sensitivities: $-56.63 \mathrm{~nm} / \mathrm{RIU}$ & [195] \\
\hline & & Temperature sensitivity: $115.3 \mathrm{pm} /{ }^{\circ} \mathrm{C}$ & \\
\hline & $\begin{array}{l}\text { Formed by a dual-core fiber with a } \\
\text { dual-side-hole fiber }\end{array}$ & Bending sensitivity: $38.53 \mathrm{~nm} / \mathrm{m}^{-1}$ & [196] \\
\hline
\end{tabular}

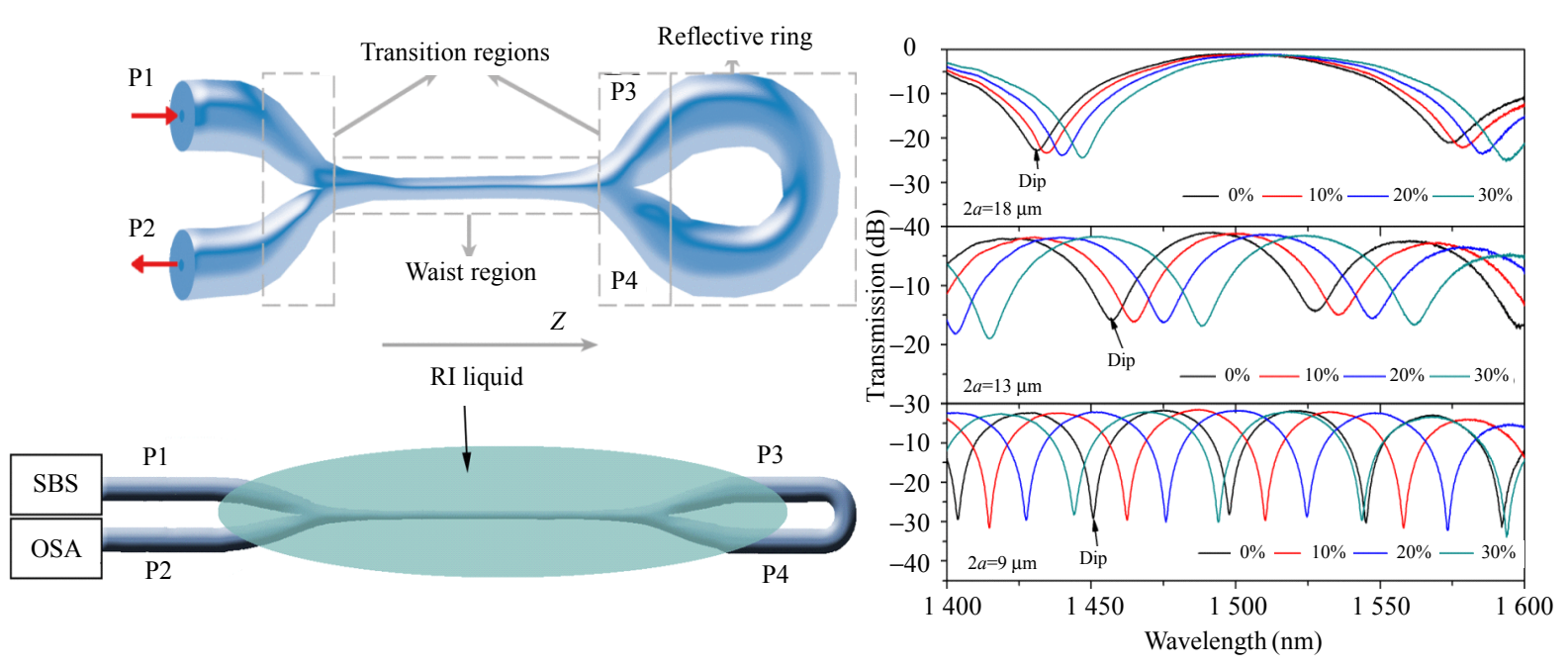

Fig. 26 Schematic diagram of the reflective tapered fiber coupler with Sagnac loop structure and its RI response [186]. 
Table 8 Sensing characteristics comparison of different SI-based FOM sensors.

\begin{tabular}{lll}
\hline Structure & Main sensing characteristics & Ref. \\
\hline A stress-induced HBF & Temperature sensitivity: $-1.00 \mathrm{~nm} / \mathrm{K}$ & {$[180]$} \\
A pressure-induced SMF & Temperature sensitivity: $0.65 \mathrm{~nm} /{ }^{\circ} \mathrm{C}$ & {$[197]$} \\
Cascaded two different types of HBFs & Temperature sensitivities: $(-1.042 \pm 0.013) \mathrm{nm} /{ }^{\circ} \mathrm{C}$ and $(-0.364 \pm 0.007) \mathrm{nm} /{ }^{\circ} \mathrm{C}$ at two & {$[181]$} \\
& dips & Strain sensitivities: $(-11.91 \pm 0.39) \mathrm{nm} / \mu \varepsilon$ and $(-25.34 \pm 0.37) \mathrm{nm} / \mu \varepsilon$ at two dips \\
SMF-PCF-SMF (PM: polarization maintaining) & Temperature sensitivities: $4.1 \mathrm{pm} /{ }^{\circ} \mathrm{C}$ and $3.8 \mathrm{pm} /{ }^{\circ} \mathrm{C}$ at two dips & {$[198]$} \\
Elliptical hollow-core PBF & Strain sensitivities: $-1.29 \mathrm{~nm} / \mu \varepsilon$ and $-1.15 \mathrm{~nm} / \mu \varepsilon$ at two dips & {$[199]$} \\
Formed by a low-birefringence PCF & Temperature sensitivity: $3.97 \mathrm{~nm} /{ }^{\circ} \mathrm{C}$ for wavelength $1474.5 \mathrm{~nm}$ & {$[185]$} \\
& Strain sensitivity: $-0.81 \mathrm{pm} / \mu \varepsilon$ for wavelength $1474.5 \mathrm{~nm}$ & Bending sensitivity: $-0.337 \mathrm{~nm} / \mathrm{m}^{-1}$ \\
Formed by a low birefringence PCF & Curvature resolution: $0.059 \mathrm{~m}{ }^{-1}$ & {$[200]$} \\
Temperature curvature-sensitivity: $0.037 \mathrm{~m}{ }^{-1} /{ }^{\circ} \mathrm{C}$ & {$[182]$} \\
Formed by a high-birefringence PCF loop mirror & Twist sensitivity: $1.00 \mathrm{~nm} /{ }^{\circ}$ & Twist resolution: $0.01^{\circ}$ \\
Formed by tapered fiber coupler & Temperature dependence: $-0.5 \mathrm{pm} /{ }^{\circ} \mathrm{C}$ \\
Formed by a PM PCF & Temperature sensitivity with uncoating: $0.29 \mathrm{pm} / \mathrm{K}$ & {$[186]$} \\
\hline
\end{tabular}

\section{Conclusions and outlook}

In this paper, the common FOM sensors, including FBG, LPFG, FPI, MZI, MI, and SI sensors, are reviewed. Each type of the FOM sensors has been introduced in the terms of structure types, fabrication methods, and their sensing applications, and the sensing characteristics of different structures sensors under the same type of FOM sensors are compared. Moreover, the sensing characteristics of all FOM sensors, including advantages, disadvantages, and advantage sensing application, are summarized, as shown in Table 9. Although the FOM sensors have been widely applied in practical environments, their improvements are still research hotspots. Therefore, FOM sensors are expected to be developed in the following areas.

(1) Development of new sensing materials and technology. Due to the rapid development of the FOM sensors in recent decades, the fiber-optic sensing technology is becoming mature gradually, especially structures of the sensors. To make further breakthroughs in the FOM sensor, combining fiber with new sensing materials and technology is a potential way in the future.

(2) Development and application of low-cost sensors in harsh environments, such as high temperature, high pressure, and nuclear radiation. Although the fiber-optic sensors have the inherent advantages of immunity to electro-magnetic interference (EMI), resistance to high-temperature $\left(1700{ }^{\circ} \mathrm{C}\right)$, resistance to corrosion, and so on, the package technology of the FOM sensor is also considered. Meanwhile, decreasing the cost of the FOM sensor is the necessary and basic factor to achieve wide applications.

(3) Development and application of the multi-parameters FOM sensors. At present, most of engineering applications often require the measurement of multiple physical parameters or eliminate the interference of other physical quantities. To reduce the complexity of the measurement system, the use of multi-parameter optical fiber sensors that measure multiple physical parameters at the same time will be an effective way in practical applications. 
Table 9 Performance comparison of different types of FOM sensors.

\begin{tabular}{|c|c|c|c|}
\hline FOM type & Advantages & Disadvantages & Advantage applications \\
\hline FBG & $\begin{array}{l}\text { +Small size } \\
\text { +Low transmission loss } \\
\text { +Mature fabrication technology } \\
\text { +Good production repeatability } \\
\text { +Long sensing distance } \\
\text { +Excellent multiplexing capacity }\end{array}$ & -Large temperature-strain crosstalk sensitivity & Temperature/strain \\
\hline LPFG & $\begin{array}{l}\text { +Low fabrication cost } \\
\text { +Low backward reflection } \\
\text { +High sensitivity } \\
\text { +Easeness to achieve multi-parameter sensing }\end{array}$ & $\begin{array}{l}\text {-Large size } \\
\text {-Low multiplexing capacity } \\
\text {-Large cross sensitivity } \\
\text {-Hard to package }\end{array}$ & $\mathrm{RI} /$ curvature \\
\hline FP & $\begin{array}{l}\text { +Small size }(\mu \mathrm{m}) \\
\text { + Low fabrication cost } \\
\text { +High sensitivity } \\
\text { +High temperature resistance } \\
\text { +Temperature insensitivity (EFPI) } \\
\text { +Applicability to harsh environments }\end{array}$ & $\begin{array}{l}\text {-Bad production repeatability } \\
\text {-Low multiplexing capacity }\end{array}$ & Pressure/sound wave/strain \\
\hline MZI & $\begin{array}{l}\text { +Small size }(\mu \mathrm{m}) \\
+ \text { Low fabrication cost } \\
+ \text { +Hight temperature resistance }\end{array}$ & $\begin{array}{l}\text {-Bad production repeatability } \\
\text {-Low multiplexing capacity }\end{array}$ & RI \\
\hline MI & $\begin{array}{l}+ \text { Small size }(\mu \mathrm{m}) \\
+ \text { Low fabrication cost }\end{array}$ & $\begin{array}{l}\text {-Large transmission loss } \\
\text {-Bad production repeatability } \\
\text {-Low multiplexing capacity }\end{array}$ & / \\
\hline SI & / & $\begin{array}{l}\text {-Single structure } \\
\text {-Low multiplexing capacity }\end{array}$ & / \\
\hline
\end{tabular}

\section{Acknowledgment}

This work was funded by the National Natural Science Foundation of China (NCSF) (Grant Nos. 51205049, 51875091, and 51327806); the state 111 Project (Grant No. B14039).

Open Access This article is distributed under the terms of the Creative Commons Attribution 4.0 International License (http://creativecommons.org/licenses/by/4.0/), which permits unrestricted use, distribution, and reproduction in any medium, provided you give appropriate credit to the original author(s) and the source, provide a link to the Creative Commons license, and indicate if changes were made.

\section{References}

[1] S. Jiang, J. Wang, and Q. Sui, "One novel type of miniaturization FBG rotation angle sensor with high measurement precision and temperature self-compensation," Photonic Sensors, 2018, 8(1): 88-96.

[2] C. Y. Lin, G. W. Chern, and L. A. Wang, "Periodical corrugated structure for forming sampled fiber Bragg grating and long-period fiber grating with tunable coupling strength," Journal of Lightwave
Technology, 2001, 19(8): 1212-1221.

[3] L. Gao, T. Zhu, M. Deng, K. S. Chiang, X. Sun, X. Dong, et al., "Long-period fiber grating within D-shaped fiber using magnetic fluid for magnetic-field detection," IEEE Photonics Journal, 2012, 4(6): 2095-2104.

[4] G. Yin, Y. Wang, C. Liao, J. Zhou, X. Zhong, G. Wang, et al., "Long period fiber gratings inscribed by periodically tapering a fiber," IEEE Photonics Technology Letters, 2014, 26(7): 698-701.

[5] T. Yang, X. He, Z. Li, Z. Xie, W. Liu, Y. Wang, et al., "Temperature insensitive fiber optic FP sensor for measurement of pressure/strain under high temperature," in 26th International Conference on Optical Fiber Sensors, Switzerland, September 24-28, 2018, pp. 1-4.

[6] T. Yang, Z. Ran, X. He, Z. Li, Z. Xie, Y. Wang, et al., "Temperature-compensated multifunctional all-fiber sensors for precise strain/high-pressure measurement," Journal of Lightwave Technology, 2019, 37(18): 4634-4642.

[7] M. Wang, M. Yang, J. Cheng, J. Dai, M. Yang, and D. N. Wang, "Femtosecond laser fabricated micro Mach-Zehnder interferometer with $\mathrm{Pd}$ film as sensing materials for hydrogen sensing," Optics Letters, 2012, 37(11): 1940-1942.

[8] B. Song, H. Zhang, B. Liu, W. Lin, and J. Wu, "Label-free in-situ real-time DNA hybridization kinetics detection employing microfiber-assisted Mach-Zehnder interferometer," Biosensors and 
Bioelectronics, 2016, 81: 151-158.

[9] L. Yuan, J. Yang, Z. Liu, and J. Sun, "In-fiber integrated Michelson interferometer," Optics Letters, 2006, 31(18): 2692-2694.

[10] S. M. A. Musa, N. F. Baharin, A. I. Azmi, R. K. R. Ibrahim, A. S. Abdullah, M. Y. M. Noor, et al., "Double-clad fiber Michelson interferometer for measurement of temperature and refractive index," Microwave and Optical Technology Letters, 2018, 60(4): 822-827.

[11] J. Ruan, "Fiber curvature sensor based on concave-heterotypic cascaded fiber Sagnac interferometer," Microwave and Optical Technology Letters, 2020, 62(11): 3645-3649.

[12] L. Y. Shao, Y. Luo, Z. Zhang, X. Zou, B. Luo, W. Pan, et al., "Sensitivity-enhanced temperature sensor with cascaded fiber optic Sagnac interferometers based on Vernier-effect," Optics Communications, 2015, 336: 73-76.

[13] V. R. Machavaram, R. A. Badcock, and G. F. Fernando, "Fabrication of intrinsic fibre Fabry-Perot sensors in silica fibres using hydrofluoric acid etching," Sensors and Actuators A: Physical, 2007, 138(1): 248-260.

[14] Z. L. Ran, Y. J. Rao, H. Y. Deng, and X. Liao, "Miniature in-line photonic crystal fiber etalon fabricated by $157 \mathrm{~nm}$ laser micromachining," Optics Letters, 2007, 32(21): 3071-3073.

[15] Y. J. Rao, M. Deng, D. W. Duan, X. C. Yang, T. Zhu, and G. H. Cheng, "Micro Fabry-Perot interferometers in silica fibers machined by femtosecond laser," Optics Express, 2007, 15(21): 14123-14128.

[16] Y. Tan, L. P. Sun, L. Jin, J. Li, and B. O. Guan, "Microfiber Mach-Zehnder interferometer based on long period grating for sensing applications," Optics Express, 2013, 21(1): 154-164.

[17] F. Wang, W. Yuan, O. Hansen, and O. Bang, "Selective filling of photonic crystal fibers using focused ion beam milled microchannels," Optics Express, 2011, 19(18): 17585-17590.

[18] K. O. Hill, B. Malo, F. Bilodeau, D. C. Johnson, and J. Albert, "Bragg gratings fabricated in monomode photosensitive optical fiber by UV exposure through a phase mask," Applied Physics Letters, 1993, 62(10): 1035-1037.

[19] K. Yang, J. He, C. Liao, Y. Wang, S. Liu, K. Guo, et al., "Femtosecond laser inscription of fiber Bragg grating in twin-core few-mode fiber for directional bend sensing," Journal of Lightwave Technology, 2017, 35(21): 4670-4676.

[20] Y. J. Rao, Y. P. Wang, Z. L. Ran, and T. Zhu, "Novel fiber-optic sensors based on long-period fiber gratings written by high-frequency $\mathrm{CO}_{2}$ laser pulses," Journal of Lightwave Technology, 2003, 21(5): 1320.

[21] M. Fujimaki, Y. Ohki, J. L. Brebner, and S. Roorda,
"Fabrication of long-period optical fiber gratings by use of ion implantation," Optics Letters, 2000, 25(2): 88-89.

[22] L. Wang, W. Zhang, L. Chen, Z. Bai, F. Liu, and T. Yan, "Torsion sensor based on two cascaded long period fiber gratings fabricated by $\mathrm{CO}_{2}$ laser pulse irradiation and HF etching technique respectively," Journal of Modern Optics, 2017, 64(5): 541-545.

[23] R. Q. Lv, Q. Wang, H. F. Hu, and J. Li, "Fabrication and sensing characterization of thermally induced long period fiber gratings in few mode fibers," Optik (Stuttg), 2018, 158: 71-77.

[24] A. D. Kersey, M. A. Davis, H. J. Patrick, M. LeBlanc, K. P. Koo, C. G. Askins, et al., "Fiber grating sensors," Journal of Lightwave Technology, 1997, 15(8): 1442-1463.

[25] D. Barrera, J. Madrigal, and S. Sales, "Tilted fiber Bragg gratings in multicore optical fibers for optical sensing," Optics Letters, 2017, 42(7): 1460-1463.

[26] T. Osuch, K. Markowski, A. Manujło, and K. Jędrzejewski, "Coupling independent fiber optic tilt and temperature sensor based on chirped tapered fiber Bragg grating in double-pass configuration," Sensors and Actuators A: Physical, 2016, 252: $76-81$.

[27] T. Osuch, K. Markowski, and K. Jedrzejewski, "Fiber-optic strain sensors based on linearly chirped tapered fiber Bragg gratings with tailored intrinsic chirp," IEEE Sensors Journal, 2016, 16(20): 7508-7514.

[28] X. Li, Y. Zhang, W. Zhang, and T. Yan, "High-sensitivity temperature-independent force sensor based on PS-LPFG formed by inserting a microbend," Journal of Optics, 2017, 19(3): 035801.

[29] H. L. Zhang, W. G. Zhang, L. Chen, Z. D. Xie, Z. Zhang, T. Y. Yan, et al., "Bidirectional torsion sensor based on a pair of helical long-period fiber gratings," IEEE Photonics Technology Letters, 2016, 28(15): 1700-1702.

[30] J. K. Sahota, N. Gupta, and D. Dhawan, "Fiber Bragg grating sensors for monitoring of physical parameters: a comprehensive review," Optical Engineering, 2020, 59(6): 060901.

[31] J. Echevarria, A. Quintela, C. Jauregui, A. Cobo, and J. M. Lopez-Higuera, "Efficient temperature and strain discimination with a single type I fiber Bragg grating transducer," in 13th Annual Meeting. IEEE Lasers and Electro-Optics Society 2000 Annual Meeting, USA, Nov. 13-16, 2000, pp. 458-459.

[32] S. Bandyopadhyay, J. Canning, M. Stevenson, and K. Cook, "Ultrahigh-temperature regenerated gratings in boron-codoped germanosilicate optical fiber using 193 nm," Optics Letters, 2008, 33(16): 1917-1919.

[33] M. Celikin, D. Barba, B. Bastola, A. Ruediger, and F. Rosei, "Development of regenerated fiber Bragg grating sensors with long-term stability," Optics Express, 2016, 24(19): 21897-21909. 
[34] J. Li, W. Zhang, S. Gao, Z. Bai, L. Wang, H. Liang, et al., "Simultaneous force and temperature measurement using $\mathrm{S}$ fiber taper in fiber Bragg grating," IEEE Photonics Technology Letters, 2013, 26(3): 309-312.

[35] J. Kong, X. Ouyang, A. Zhou, H. Yu, and L. Yuan, "Pure directional bending measurement with a fiber Bragg grating at the connection joint of eccentric-core and single-mode fibers," Journal of Lightwave Technology, 2016, 34(14): 3288-3292.

[36] A. G. Simpson, K. Kalli, L. Zhang, K. Zhou, and I. Bennion, "Type 1A fibre Bragg grating photosensitivity and the development of optimum temperature invariant type I-type IA strain sensors," in Photonics Europe, France, 2004, pp. 5459.

[37] C. W. Smelser, S. J. Mihailov, and D. Grobnic, "Formation of Type I-IR and Type II-IR gratings with an ultrafast IR laser and a phase mask," Optics Express, 2005, 13(14): 5377-5386.

[38] X. Shu, D. Zhao, Y. Liu, B. Gwandu, F. Floreani, and L. Zhang, "Effectively simultaneous temperature and strain type IA and type IIA FBGs," in Sensors, Proceedings of IEEE, 2002, pp. 2-45.

[39] H. Z. Yang, M. M. Ali, M. R. Islam, K. S. Lim, D. S. Gunawardena, and H. Ahmad, "Cladless few mode fiber grating sensor for simultaneous refractive index and temperature measurement," Sensors and Actuators A: Physical, 2015, 228: 62-68.

[40] Y. Zhang, W. Zhang, Y. Zhang, S. Wang, L. Yu, and Y. Yan, "Simultaneous measurement of curvature and temperature based on LP11 mode Bragg grating in seven-core fiber," Measurement Science and Technology, 2017, 28(5): 055101.

[41] D. Barrera, I. Gasulla, and S. Sales, "Multipoint two-dimensional curvature optical fiber sensor based on a nontwisted homogeneous four-core fiber," Journal of Lightwave Technology, 2015, 33(12): 2445-2450.

[42] C. Wang, J. He, J. Zhang, C. Liao, Y. Wang, W. Jin, et al., "Bragg gratings inscribed in selectively inflated photonic crystal fibers," Optics Express, 2017, 25(23): 28442-28450.

[43] X. Zhang and W. Peng, "Fiber Bragg grating inscribed in dual-core photonic crystal fiber," IEEE Photonics Technology Letters, 2015, 27(4): 391-394.

[44] Z. Wu, H. Zhang, P. P. Shum, X. Shao, T. Huang, Y. M. Seow, et al., "Supermode Bragg grating combined Mach-Zehnder interferometer for temperature-strain discrimination," Optics Express, 2015, 23(26): 33001-33007.

[45] B. Jiang, Z. Bai, C. Wang, Y. Zhao, J. Zhao, L. Zhang, et al., "In-line Mach-Zehnder interferometer with D-shaped fiber grating for temperaturediscriminated directional curvature measurement," Journal of Lightwave Technology, 2018, 36(3): 742-747.

[46] B. C. Yao, Y. Wu, D. J. Webb, J. H. Zhou, Y. J. Rao,
A. Pospori, et al., "Graphene-based D-shaped polymer FBG for highly sensitive erythrocyte detection," IEEE Photonics Technology Letters, 2015, 27(22): 2399-2402.

[47] D. Grobnic, S. J. Mihailov, C. W. Smelser, and H. Ding, "Sapphire fiber Bragg grating sensor made using femtosecond laser radiation for ultrahigh temperature applications," IEEE Photonics Technology Letters, 2004, 16(11): 2505-2507.

[48] D. Grobnic, S. J. Mihailov, H. Ding, F. Bilodeau, and C. W. Smelser, "Single and low order mode interrogation of a multimode sapphire fiber Bragg grating sensor with tapered fibers," Measurement Science and Technology, 2006, 17(5): 980.

[49] C. Zhan, J. H. Kim, J. Lee, S. Yin, P. Ruffin, and C. Luo, "High temperature sensing using higher-order-mode rejected sapphire-crystal fiber gratings," in Optical Engineering + Applications, San Diego, 2007, pp. 66980F.

[50] K. Kalli, T. Geernaert, C. Koutsides, M. Komodromos, T. Nasilowski, W. Urbanczyk, et al., "Point-by-point Bragg grating inscription in single-mode microstructure fibre using NIR femtosecond laser," in 20th International Conference on Optical Fibre Sensors, United Kingdom, 2009, pp. $75037 \mathrm{O}$.

[51] S. Yang, D. Hu, and A. Wang, "Point-by-point fabrication and characterization of sapphire fiber Bragg gratings," Optics Letters, 2017, 42(20): 4219-4222.

[52] X. Xu, J. He, C. Liao, K. Yang, K. Guo, C. Li, et al., "Sapphire fiber Bragg gratings inscribed with a femtosecond laser line-by-line scanning technique," Optics Letters, 2018, 43(19): 4562-4565.

[53] Z. Bai, W. Zhang, S. Gao, P. Geng, H. Zhang, J. Li, et al., "Compact long period fiber grating based on periodic micro-core-offset," IEEE Photonics Technology Letters, 2013, 25(21): 2111-2114.

[54] T. Zhu, Y. Song, Y. Rao, and Y. Zhu, "Highly sensitive optical refractometer based on edge-written ultra-long-period fiber grating formed by periodic grooves," IEEE Sensors Journal, 2009, 9(6): 678-681.

[55] Y. P. Li, L. Chen, Y. X. Zhang, W. G. Zhang, S. Wang, Y. S. Zhang, et al., "Realizing torsion detection using berry phase in an angle-chirped long-period fiber grating," Optics Express, 2017, 25(12): 13448-13454.

[56] Y. P. Li et al., "Realizing torsion detection using berry phase in an angle-chirped long-period fiber grating," Opt. Express, vol. 25, no. 12, pp. 13448, 2017.

[57] R. B. Shang, W. G. Zhang, W. B. Zhu, P. C. Geng, J. Ruan, S. C. Gao, et al., "Fabrication of twisted long period fiber gratings with high frequency $\mathrm{CO}_{2}$ laser pulses and its bend sensing," Journal of Optics (United Kingdom), 2013, 15(7): 075402. 
[58] S. Oh, K. R. Lee, U. C. Paek, and Y. Chung, "Fabrication of helical long-period fiber gratings by use of a $\mathrm{CO}_{2}$ laser," Optics Letters, 2004, 29(13): 1464-1466.

[59] Y. P. Wang and Y. J. Rao, "A novel long period fiber grating sensors measuring bend-curvature and determining bend-direction simultaneously," IEEE Sensors Journal, 2005, 5(5): 839-843.

[60] P. Geng, W. Zhang, S. Gao, H. Zhang, J. Li, S. Zhang, et al., "Two-dimensional bending vector sensing based on spatial cascaded orthogonal long period fiber," Optics Express, 2012, 20(27): 28557-28562.

[61] J. Li, W. Zhang, S. Gao, P. Geng, X. Xue, Z. Bai, et al., "Long-period fiber grating cascaded to an $\mathrm{S}$ fiber taper for simultaneous measurement of temperature and refractive index," IEEE Photonics Technology Letters, 2013, 25(9): 888-891.

[62] T. Habisreuther, T. Elsmann, Z. Pan, A. Graf, R. Willsch, and M. A. Schmidt, "Sapphire fiber Bragg gratings for high temperature and dynamic temperature diagnostics," Applied Thermal Engineering, 2015, 91: 860-865.

[63] S. Yang, D. Homa, G. Pickrell, and A. Wang, "Fiber Bragg grating fabricated in micro-single-crystal sapphire fiber," Optics Letters, 2018, 43(1): 62-65.

[64] F. Ahmed and M. B. G. Jun, "Microfiber Bragg grating sandwiched between standard optical fibers for enhanced temperature sensing," IEEE Photonics Technology Letters, 2016, 28(6): 685-688.

[65] C. Liao, Q. Wang, L. Xu, S. Liu, J. He, J. Zhao, et al., "D-shaped fiber grating refractive index sensor induced by an ultrashort pulse laser," Applied Optics, 2016, 55(7): 1525-1529.

[66] Z. Cai, F. Liu, T. Guo, B. O. Guan, G. D. Peng, and J. Albert, "Evanescently coupled optical fiber refractometer based a tilted fiber Bragg grating and a D-shaped fiber," Optics Express, 2015, 23(16): 20971-20976.

[67] T. Wang, K. Liu, J. Jiang, M. Xue, P. Chang, and T. Liu, "Temperature-insensitive refractive index sensor based on tilted moiré FBG with high resolution," Optics Express, 2017, 25(13): 14900-14909.

[68] X. Chen, J. Xu, X. Zhang, T. Guo, and B. O. Guan, "Wide range refractive index measurement using a multi-angle tilted fiber Bragg grating," IEEE Photonics Technology Letters, 2017, 29(9): 719-722.

[69] S. Korganbayev, Y. Orazayev, S. Sovetov, A. Bazyl, E. Schena, C. Massaroni, et al., "Detection of thermal gradients through fiber-optic chirped fiber Bragg grating (CFBG): medical thermal ablation scenario," Optical Fiber Technology, 2018, 41: 48-55.

[70] X. Qiao, Y. Wang, H. Yang, T. Guo, Q. Rong, L. Li, et al., "Ultrahigh-temperature chirped fiber Bragg grating through thermal activation," IEEE Photonics Technology Letters, 2015, 27(12): 1305-1308.
[71] J. Guo and C. Yang, "Highly stabilized phase-shifted fiber Bragg grating sensing system for ultrasonic detection," IEEE Photonics Technology Letters, 2015, 27(8): 848-851.

[72] D. Gatti, G. Galzerano, D. Janner, S. Longhi, and P. Laporta, "Fiber strain sensor based on a $\pi$-phase-shifted Bragg grating and the Pound-Drever-Hall technique," Optics Express, 2008, 16(3): 1945-1950.

[73] B. Wang, W. Zhang, Z. Bai, L. Wang, L. Zhang, Q. Zhou, et al., " $\mathrm{CO}_{2}$-laser-induced long period fiber gratings in few mode fibers," IEEE Photonics Technology Letters, 2014, 27(2): 145-148.

[74] L. Wang, W. Zhang, B. Wang, L. Chen, Z. Bai, S. Gao, et al., "Simultaneous strain and temperature measurement by cascading few-mode fiber and single-mode fiber long-period fiber gratings," Applied Optics, 2014, 53(30): 7045-7049.

[75] D. Barrera, J. Madrigal, and S. Sales, "Long period gratings in multicore optical fibers for directional curvature sensor implementation," Journal of Lightwave Technology, 2018, 36(4): 1063-1068.

[76] X. Shen, X. Hu, L. Yang, N. Dai, J. Wu, F. Zhang, et al., "Helical long-period grating manufactured with a $\mathrm{CO}_{2}$ laser on multicore fiber," Optics Express, 2017, 25(9): 10405-10412.

[77] N. Zhang, G. Humbert, Z. Wu, K. Li, P. P. Shum, N. M. Y. Zhang, et al., "In-line optofluidic refractive index sensing in a side-channel photonic crystal fiber," Optics Express, 2016, 24(24): 27674-27682.

[78] C. Du, Q. Wang, Y. Zhao, and J. Li, "Highly sensitive temperature sensor based on an isopropanol-filled photonic crystal fiber long period grating," Optical Fiber Technology, 2017, 34: $12-15$.

[79] Z. He, Y. Zhu, and H. Du, "Long-period gratings inscribed in air- and water-filled photonic crystal fiber for refractometric sensing of aqueous solution," Applied Physics Letters, 2008, 92(4): 044105.

[80] S. M. Tripathi, E. Marin, A. Kumar, and J. P. Meunier, "Refractive index sensing characteristics of dual resonance long period gratings in bare and metal-coated D-shaped fibers," Applied Optics, 2009, 48(31): G53-G58.

[81] G. Quero, A. Crescitelli, D. Paladino, M. Consalesa, A.Buosciolo, M.Giordano, et al., "Evanescent wave long-period fiber grating within D-shaped optical fibers for high sensitivity refractive index detection," Sensors and Actuators B: Chemical, 2011, 152(2): 196-205.

[82] C. E. Lee, R. A. Atkins, and H. F. Taylor, "Performance of a fiber-optic temperature sensor from -200 to $1050{ }^{\circ} \mathrm{C}$," Optics Letters, 1988, 13(11): 1038-1040.

[83] J. Mathew, O. Schneller, D. Polyzos, D. Havermann, R. M. Carter, W. N. MacPherson, et al., "In-fiber Fabry-Perot cavity sensor for high-temperature 
applications," Journal of Lightwave Technology, 2015, 33(12): 2419-2425.

[84] Y. P. Wang, L. Xiao, D. N. Wang, and W. Jin, "Highly sensitive long-period fiber-grating strain sensor with low temperature sensitivity," Optics Letters, 2006, 31(23): 3414-3416.

[85] Y. P. Wang, D. N. Wang, and W. Jin, " $\mathrm{CO}_{2}$ laser-grooved long period fiber grating temperature sensor system based on the intensity modulation," Applied Optics, 2006, 45(31): 7966-7970.

[86] T. Zhu, Y. J. Rao, Y. Song, K. S. Chiang, and M. Liu, "Highly sensitive temperature-independent strain sensor based on a long-period fiber grating with a $\mathrm{CO}_{2}$-laser engraved rotary structure," IEEE Photonics Technology Letters, 2009, 21(8): 543-545.

[87] T. Yuan, X. Zhong, C. Guan, J. Fu, J. Yang, J. Shi, et al., "Long period fiber grating in two-core hollow eccentric fiber," Optics Express, 2015, 23(26): 33378-33385.

[88] X. Jin, C. Sun, S. Duan, W. Liu, G. Li, S. Zhang, et al., "High strain sensitivity temperature sensor based on a secondary modulated tapered long period fiber grating," IEEE Photonics Journal, 2019, 11(1): $1-8$.

[89] W. J. Bock, J. Chen, P. Mikulic, and T. Eftimov, “A novel fiber-optic tapered long-period grating sensor for pressure monitoring," IEEE Transactions on Instrumentation and Measurement, 2007, 56(4): 1176-1180.

[90] W. J. Bock, J. Chen, P. Mikulic, T. Eftimov, and M. Korwin-Pawlowski, "Pressure sensing using periodically tapered long-period gratings written in photonic crystal fibres," Measurement Science and Technology, 2007, 18(10): 3098.

[91] H. Hu, C. Du, Q. Wang, X. Wang, and Y. Zhao, "High sensitivity internal refractive index sensor based on a photonic crystal fiber long period grating," Instrumentation Science \& Technology, 2017, 45(2): 181-189.

[92] J. Tang, G. Yin, S. Liu, X. Zhong, C. Liao, Z. Li, et al., "Gas pressure sensor based on $\mathrm{CO}_{2}$-laser-induced long-period fiber grating in air-core photonic bandgap fiber," IEEE Photonics Journal, 2015, 7(5): 1-7.

[93] M. Yang, D. N. Wang, Y. Wang, and C. Liao, "Long period fiber grating formed by periodically structured microholes in all-solid photonic bandgap fiber," Optics Express, 2010, 18(3): 2183-2189.

[94] J. C. Guo, Y. S. Yu, Y. Xue, C. Chen, R. Yang, C. Wang, et al., "Compact long-period fiber gratings based on periodic microchannels," IEEE Photonics Technology Letters, 2012, 25(2): 111-114.

[95] B. Sun, W. Wei, C. Liao, L. Zhang, Z. Zhang, M. Y. Chen, et al., "Automatic arc discharge-induced helical long period fiber gratings and its sensing applications," IEEE Photonics Technology Letters, 2017, 29(11): 873-876.
[96] Z. Li, S. Liu, Z. Bai, C. Fu, Y. Zhang, Z. Sun, et al., "Residual-stress-induced helical long period fiber gratings for sensing applications," Optics Express, 2018, 26(18): 24114-24123.

[97]H. Zhang, Z. Wu, P. P. Shum, X. Q. Dinh, C. W. Low, $\mathrm{Z}$. $\mathrm{Xu}$, et al., "Highly sensitive strain sensor based on helical structure combined with Mach-Zehnder interferometer in multicore fiber," Scientific Reports, 2017, 7(1): 1-10.

[98] X. Zhong, Y. Wang, J. Qu, C. Liao, S. Liu, J. Tang, et al., "High-sensitivity strain sensor based on inflated long period fiber grating," Optics Letters, 2014, 39(18): 5463-5466.

[99] X. Zhong, Y. Wang, C. Liao, S. Liu, J. Tang, and Q. Wang, "Temperature-intensitivity gas pressure sensor based on inflated long period fiber grating inscribed in photonic crystal fiber," Optics Letters, 2015, 40(8): 1791-1794.

[100] Y. F. Zhang, C. C. Chan, Y. M. Chan, and P. Zu, "Tilted long period gratings pressure sensing in solid core photonic crystal fibers," IEEE Sensors Journal, 2011, 12(5): 954-957.

[101] J. Tang, C. Fu, Z. Bai, C. Liao, and Y. Wang, "Sensing characteristics of tilted long period fiber gratings inscribed by infrared femtosecond laser," Sensors (Switzerland), 2018, 18(9): 3003.

[102] P. Wang, L. Xian, and H. Li, "Fabrication of phase-shifted long-period fiber grating and its application to strain measurement," IEEE Photonics Technology Letters, 2014, 27(5): 557-560.

[103] S. Niu, Y. Liao, Q. Yao, and Y. Hu, "Resolution and sensitivity enhancements in strong grating based fiber Fabry-Perot interferometric sensor system utilizing multiple reflection beams," Optics Communications, 2012, 285(12): 2826-2831.

[104]X. Chen, F. Shen, Z. Wang, Z. Huang, and A. Wang, "Micro-air-gap based intrinsic Fabry-Perot interferometer fiber-optic sensor," Applied Optics, 2006, 45(30): 7760-7766.

[105] Z. Huang, Y. Zhu, X. Chen, and A. Wang, "Intrinsic Fabry-Pérot fiber sensor for temperature and strain measurements," IEEE Photonics Technology Letters, 2005, 17(11): 2403-2405.

[106] P. C. Fiber, "A miniature Fabry-Pérot interferometer for high temperature measurement using a double-core photonic crystal fiber," IEEE Sensors Journal, 2013, 14(4): 1069-1073.

[107] P. Chen, X. Shu, and H. Cao, "Novel compact and low-cost ultraweak Fabry-Perot interferometer as a highly sensitive refractive index sensor," IEEE Photonics Journal, 2017, 9(5): 1-10.

[108] A. Wang, S. Gollapudi, K. A. Murphy, R. G. May, and R. Claus, "Sapphire-fiber-based intrinsic Fabry-Perot interferometer," Optics Letters, 1992, 17(14): 1021-1023.

[109] C. L. Lee, J. M. Hsu, J. S. Horng, W. Y. Sung, and 
C. M. Li, "Microcavity fiber Fabry-Pérot interferometer with an embedded golden thin film," IEEE Photonics Technology Letters, 2013, 25(9): 833-836.

[110] S. H. Aref, H. Latifi, M. I. Zibaii, and M. Afshari, "Fiber optic Fabry-Perot pressure sensor with low sensitivity to temperature changes for downhole application," Optics Communications, 2007, 269(2): 322-330.

[111] Y. Jiang and C. Tang, "High-finesse micro-lens fiber-optic extrinsic Fabry-Perot interferometric sensors," Smart Materials and Structures, 2008, 17(5): 055013.

[112] O. Frazão, J. M. Baptista, J. L. Santos, J. Kobelke, and K. Schuster, "Refractive index tip sensor based on Fabry-Perot cavities formed by a suspended core fibre," Journal of the European Optical Society-Rapid publications, 2009, 4: 28-31.

[113] Y. J. Rao, M. Deng, D. W. Duan, and T. Zhu, "In-line fiber Fabry-Perot refractive-index tip sensor based on endlessly photonic crystal fiber," Sensors and Actuators A: Physical, 2008, 148(1): 33-38.

[114] H. Y. Choi, K. S. Park, S. J. Park, U. C. Paek, B. H. Lee, and E. S. Choi, "Miniature fiber-optic high temperature sensor based on a hybrid structured Fabry-Perot interferometer," Optics Letters, 2008, 33(21): 2455-2457.

[115] S. Silva, L. Coelho, and O. Frazão, “An all-fiber Fabry-Pérot interferometer for pressure sensing in different gaseous environments," Measurement, 2014, 47: 418-421.

[116] D. Donlagic and E. Cibula, "All-fiber highsensitivity pressure sensor with $\mathrm{SiO}_{2}$ diaphragm," Optics Letters, 2005, 30(16): 2071-2073.

[117] F. Interferometer, W. Wang, Q. Yu, F. Li, X. Zhou, and $\mathrm{X}$. Jiang, "Temperature-insensitive pressure sensor based on all-fused-silica extrinsic Fabry-Pérot optical," IEEE Sensors Journal, 2012, 12(7): 2425-2429.

[118] M. J. Gander, W. N. MacPherson, J. S. Barton, R. L. Reuben, J. D. C. Jones, R. Stevens, et al., "Embedded micromachined fiber-optic Fabry-Perot pressure sensors in aerodynamics applications," IEEE Sensors Journal, 2003, 3(1): 102-107.

[119] H. Bae and M. Yu, "Miniature Fabry-Perot pressure sensor created by using UV-molding process with an optical fiber based mold," Optics Express, 2012, 20(13): 14573-14583.

[120]L. H. Chen, X. M. Ang, C. C. Chan, M. Shaillender, B. Neu, W. C. Wong, et al., "Layer-by-layer (chitosan/ polystyrene sulfonate) membrane-based fabry-perot interferometric fiber optic biosensor," IEEE Journal of Selected Topics in Quantum Electronics, 2012, 18(4): 1457-1464.

[121] J. Ma, H. Xuan, H. L. Ho, W. Jin, Y. Yang, and S. Fan, "Fiber-optic Fabry-Pérot acoustic sensor with multilayer graphene diaphragm," IEEE Photonics Technology Letters, 2013, 25(10): 932-935.

[122] F. J. Arregui, K. L. Cooper, Y. Liu, I. R. Matias, and R. O. Claus, "Optical fiber humidity sensor with a fast response time using the ionic self-assembly method," IEICE Transactions on Electronics, 2000, 83(3): 360-365.

[123] B. T. Cox, E. Z. Zhang, J. G. Laufer, and P. C. Beard, "Fabry Perot polymer film fibre-optic hydrophones and arrays for ultrasound field characterisation," Journal of Physics: Conference Series, 2004, 1: 32-37.

[124] T. Wei, Y. Han, Y. Li, H. L. Tsai, and H. Xiao, "Temperature-insensitive miniatureized fiber inline Fabry-Perot interferometer for highly sensitive refractive index measurement," Optics Express, 2008, 16(8): 5764-5769.

[125] Y. Gong, Y. J. Rao, Y. Guo, Z. L. Ran, and Y. Wu, "Temperature-insensitive micro Fabry-Pérot strain sensor fabricated by chemically etching Er-doped fiber," IEEE Photonics Technology Letters, 2009, 21(22): 1725-1727.

[126] Z. L. Ran, Y. J. Rao, W. J. Liu, X. Liao, and K. S. Chiang, "Laser-micromachined Fabry-Perot optical fiber tip sensor for high-resolution temperatureindependent measurement of refractive index," Optics Express, 2008, 16(3): 2252-2263.

[127] Z. Ran, Z. Liu, Y. Rao, F. Xu, D. Sun, X. Yu, et al., "Miniature fiber-optic tip high pressure sensors micromachined by $157 \mathrm{~nm}$ laser," IEEE Sensors Journal, 2011, 11(5): 1103-1106.

[128] Z. L. Ran, Y. J. Rao, H. Y. Deng, and X. Liao, "Miniature in-line photonic crystal fiber etalon fabricated by $157 \mathrm{~nm}$ laser micromachining," Optics Letters, 2007, 32(21): 3071-3073.

[129] X. Wan and H. F. Taylor, "Intrinsic fiber Fabry-Perot temperature sensor with fiber Bragg grating mirrors," Optics Letters, 2002, 27(16): 1388-1390.

[130] Y. J. Rao, M. R. Cooper, D. A. Jackson, C. N. Pannell, and L. Reekie, "Absolute strain measurement using an in-fiber-Bragg-grating-based Fabry-Perot sensor," Electronics Letters, 2000, 36(8): 708-709.

[131] Y. J. Rao, M. Deng, D. W. Duan, and T. Zhu, "In-line fiber Fabry-Perot refractive-index tip sensor based on endlessly photonic crystal fiber," Sensors and Actuators A: Physical, 2008, 148(1): 33-38.

[132] J. J. Zhu, A. P. Zhang, T. H. Xia, S. He, and W. Xue, "Fiber-optic high-temperature sensor based on thin-core fiber modal interferometer," IEEE Sensors Journal, 2010, 10(9): 1415-1418.

[133] Q. Zhao, H. Li, J. Lv, X. Liu, F. Zhang, S. Jiang, et al., "Adhesive-free bonding fiber optic Fabry-Perot pressure sensor based on oxy-hydrogen 
flame welding and spiral tube," Optics Communications, 2020, 476: 126307.

[134] F. Guo, T. Fink, M. Han, L. Koester, J. Turner, and J. Huang, "High-sensitivity, high-frequency extrinsic Fabry-Perot interferometric fiber-tip sensor based on a thin silver diaphragm," Optics Letters, 2012, 37(9): 1505-1507.

[135] J. Ma, W. Jin, H. L. Ho, and J. Y. Dai, "High-sensitivity fiber-tip pressure sensor with graphene diaphragm," Optics Letters, 2012, 37(13): 2493-2495.

[136] J. Xu, G. Pickrell, X. Wang, W. Peng, K. Cooper, and A. Wang, "A novel temperature-insensitive optical fiber pressure sensor for harsh environments," IEEE Photonics Technology Letters, 2005, 17(4): 870-872.

[137] S. Liu, K. Yang, Y. Wang, J. Qu, C. Liao, J. He, et al., "High-sensitivity strain sensor based on in-fiber rectangular air bubble," Scientific Reports, 2015, 5(1): 1-7.

[138] S. Pevec and D. Donlagic, "All-fiber, long-activelength Fabry-Perot strain sensor," Optics Express, 2011, 19(16): 15641-15651.

[139] J. F. Ding, A. P. Zhang, L. Y. Shao, J. H. Yan, and S. He, "Fiber-taper seeded long-period grating pair as a highly sensitive refractive-index sensor," IEEE Photonics Technology Letters, 2005, 17(6): 1247-1249.

[140] J. H. Lim, H. S. Jang, K. S. Lee, J. C. Kim, and B. H. Lee, "Mach-Zehnder interferometer formed in a photonic crystal fiber based on a pair of long-period fiber gratings," Optics Letters, 2004, 29(4): 346-348.

[141] H. Y. Choi, M. J. Kim, and B. H. Lee, "Compact all-fiber Mach-Zehnder interferometers formed in photonic crystal fiber," Optics Express, 2007, 15(9): 5711-5720.

[142] L. V. Nguyen, D. Hwang, S. Moon, D. S. Moon, and Y. Chung, "High temperature fiber sensor with high sensitivity based on core diameter mismatch," Optics Express, 2008, 16(15): 11369-11375.

[143] L. Men, P. Lu, and Q. Chen, "Femtosecond laser trimmed fiber taper for simultaneous measurement of axial strain and temperature," IEEE Photonics Technology Letters, 2011, 23(5): 320-322.

[144] L. Zhao, L. Jiang, S. Wang, H. Xiao, Y. Lu, and H. L. Tsai, "A high-quality Mach-Zehnder interferometer fiber sensor by femtosecond laser one-step processing," Sensors, 2011, 11(1): 54-61.

[145] H. Gong, D. N. Wang, B. Xu, K. Ni, H. Liu, and C. L. Zhao, "Miniature and robust optical fiber in-line Mach-Zehnder interferometer based on a hollow ellipsoid," Optics Letters, 2015, 40(15): 3516-3519.

[146]Z. Li, C. Liao, D. Chen, J. Song, W. Jin, G. D. Peng, et al., "Label-free detection of bovine serum albumin based on an in-fiber Mach-Zehnder interferometric biosensor," Optics Express, 2017, 25(15): 17105-17113.

[147] T. Y. Hu and D. N. Wang, "Optical fiber in-line Mach-Zehnder interferometer based on dual internal mirrors formed by a hollow sphere pair," Optics Letters, 2013, 38(16): 3036-3039.

[148] J. Liu, D. N. Wang, and L. Zhang, "Slightly tapered optical fiber with dual inner air-cavities for simultaneous refractive index and temperature measurement," Journal of Lightwave Technology, 2016, 34(21): 4872-4876.

[149] J. Liu, C. Luo, H. Yang, Z. Yi, B. Liu, X. He, et al., "Mach-Zehnder interferometer for high temperature $\left(1000{ }^{\circ} \mathrm{C}\right)$ sensing based on a few-mode fiber," Photonic Sensors, 2020, DOI: 10.1007/s13320-020-0596-z.

[150] L. Li, L. Xia, Z. Xie, and D. Liu, "All-fiber Mach-Zehnder interferometers for sensing applications," Optics Express, 2012, 20(10): 11109-11120.

[151] J. Zheng, P. Yan, Y. Yu, Z. Ou, J. Wang, X. Chen, et al., "Temperature and index insensitive strain sensor based on a photonic crystal fiber in line Mach-Zehnder interferometer," Optics Communications, 2013, 297: 7-11.

[152] J. Zhou, C. Liao, Y. Wang, G. Yin, X. Zhong, K. Yang, et al., "Simultaneous measurement of strain and temperature by employing fiber Mach-Zehnder interferometer," Optics Express, 2014, 22(2): 1680-1686.

[153] Q. Rong, X. Qiao, R. Wang, H. Sun, M. Hu, and Z. Feng, "High-sensitive fiber-optic refractometer based on a core-diameter-mismatch Mach-Zehnder interferometer," IEEE Sensors Journal, 2012, 12(7): 2501-2505.

[154] Q. Wang, L. X. Kong, Y. L. Deng, F. Xia, et al., "High sensitivity refractive index sensor based on splicing points tapered SMF-PCF-SMF structure Mach-Zehnder mode interferometer," Sensors Actuators B Chem., 2016, vol. 225, pp. 213-220.

[155] R. Wang, J. Zhang, Y. Weng, Q. Rong, Y. Ma, Z. Feng, et al., "Highly sensitive curvature sensor using an in-fiber Mach-Zehnder interferometer," IEEE Sensors Journal, 2013, 13(5): 1766-1770.

[156] Y. Zhao, M. Q. Chen, F. Xia, L. Cai, and X. G. Li, "Small curvature sensor based on butterfly-shaped Mach-Zehnder interferometer," IEEE Transactions on Electron Devices, 2017, 64(11): 4644-4649.

[157] X. Sun, H. Du, X. Dong, Y. Hu, and J. Duan, "Simultaneous curvature and temperature sensing based on a novel Mach-Zehnder interferometer," Photonic Sensors, 2020, 10(2): 171-180.

[158] P. Lu, L. Men, K. Sooley, and Q. Chen, "Tapered fiber Mach-Zehnder interferometer for simultaneous measurement of refractive index and temperature," Applied Physics Letters, 2009, 94(13): 131110. 
[159] Z. Tian and S. S. H. Yam, "In-line abrupt taper optical fiber Mach-Zehnder interferometric strain sensor," IEEE Photonics Technology Letters, 2008, 21(3): 161-163.

[160] Z. Tian, S. S. H. Yam, J. Barnes, W. Bock, P. Greig, J. M. Fraser, et al., "Refractive index sensing with Mach-Zehnder interferometer based on concatenating two single-mode fiber tapers," IEEE Photonics Technology Letters, 2008, 20(8): 626-628.

[161] Q. Wang, W. Wei, M. Guo, and Y. Zhao, "Optimization of cascaded fiber tapered Mach-Zehnder interferometer and refractive index sensing technology," Sensors and Actuators B: Chemical, 2016, 222: 159-165.

[162] D. W. Duan, Y. J. Rao, L. C. Xu, T. Zhu, D. Wu, and J. Yao, "In-fiber Mach-Zehnder interferometer formed by large lateral offset fusion splicing for gases refractive index measurement with high sensitivity," Sensors and Actuators B: Chemical, 2011, 160(1): 1198-1202.

[163] O. Frazão, S. F. O. Silva, J. Viegas, J. M. Baptista, J. L. Santos, J. Kobelke, et al., "All fiber Mach-Zehnder interferometer based on suspended twin-core fiber," IEEE Photonics Technology Letters, 2010, 22(17): 1300-1302.

[164] M. Deng, C. P. Tang, T. Zhu, and Y. J. Rao, “Highly sensitive bend sensor based on Mach-Zehnder interferometer using photonic crystal fiber," Optics Communications, 2011, 284(12): 2849-2853.

[165] C. R. Liao, D. N. Wang, and Y. Wang, "Microfiber in-line Mach-Zehnder interferometer for strain sensing," Optics Letters, 2013, 38(5): 757-759.

[166] Y. Wang, Y. Li, C. Liao, D. N. Wang, M. Yang, and P. Lu, "High-temperature sensing using miniaturized fiber in-line Mach-Zehnder interferometer," IEEE Photonics Technology Letters, 2009, 22(1): 39-41.

[167] Y. Wang, M. Yang, D. N. Wang, S. Liu, and P. Lu, "Fiber in-line Mach-Zehnder interferometer fabricated by femtosecond laser micromachining for refractive index measurement with high sensitivity," Journal of the Optical Society of America B, 2010, 27(3): 370-374.

[168] L. Jiang, J. Yang, S. Wang, B. Li, and M. Wang, "Fiber Mach-Zehnder interferometer based on microcavities for high-temperature sensing with high sensitivity," Optics Letters, 2011, 36(19): 3753-3755.

[169] X. Zhou, K. Chen, X. Mao, W. Peng, and Q. Yu, "High-resolution optical refractometer based on a long-period grating Michelson interferometer using a cross-correlation signal-processing method," Optical Engineering, 2015, 54(12): 126108.

[170] P. Sandhu, J. Yang, and C. Q. Xu, "In-fiber Michelson interferometer with polymeric/ nanoparticle thin-film overlay as a platform for biosensing," IEEE Journal of Selected Topics in Quantum Electronics, 2009, 16(3): 685-690.

[171] C. R. Liao, D. N. Wang, M. Wang, and M. Yang, "Fiber in-line Michelson interferometer tip sensor fabricated by femtosecond laser," IEEE Photonics Technology Letters, 2012, 24(22): 2060-2063.

[172] L. Yuan, T. Wei, Q. Han, H. Wang, J. Huang, L. Jiang, et al., "Fiber in-line Michelson interferometer fabricated by femtosecond laser," Optics Letters, 2012, 37(21): 4489-4491.

[173]Q. Rong, X. Qiao, Y. Du, H. Sun, D. Feng, R. Wang, et al., "In-fiber quasi-Michelson interferometer for liquid level measurement with a core-cladding-modes fiber end-face mirror," Optics and Lasers in Engineering, 2014, 57: 53-57.

[174] Z. Li, Y. Wang, C. Liao, S. Liu, J. Zhou, X. Zhong, et al., "Temperature-insensitive refractive index sensor based on in-fiber Michelson interferometer," Sensors and Actuators B: Chemical, 2014, 199: 31-35.

[175] M. Shao, L. Han, H. Sun, X. Yin, and X. Qiao, "A liquid refractive index sensor based on 3-core fiber Michelson interferometer," Optics Communications, 2019, 453: 124356.

[176] H. Cao and X. Shu, "Miniature all-fiber high temperature sensor based on Michelson interferometer formed with a novel coremismatching fiber joint," IEEE Sensors Journal, 2017, 17(11): 3341-3345.

[177] B. Wang, K. Ni, P. Wang, Q. Ma, W. Tian, and L. Tan, "A CNT-coated refractive index sensor based on Michelson interferometer with thin-core fiber," Optical Fiber Technology, 2018, 46: 302-305.

[178] A. Zhou, G. Li, Y. Zhang, Y. Wang, C. Guan, J. Yang, et al., "Asymmetrical twin-core fiber based michelson interferometer for refractive index sensing," Journal of Lightwave Technology, 2011, 29(19): 2985-2991.

[179] J. Zhou, Y. Wang, C. Liao, B. Sun, J. He, G. Yin, et al., "Intensity modulated refractive index sensor based on optical fiber Michelson interferometer," Sensors and Actuators B: Chemical, 2015, 208: 315-319.

[180] E. D. la Rosa, L. A. Zenteno, A. N. Starodumov, and D. Monzon, "All-fiber absolute temperature sensor using an unbalanced high-birefringence Sagnac loop," Optics Letters, 1997, 22(7): 481-483.

[181] G. Sun, D. S. Moon, and Y. Chung, "Simultaneous temperature and strain measurement using two types of high-birefringence fibers in Sagnac loop mirror," IEEE Photonics Technology Letters, 2007, 19(24): 2027-2029.

[182] O. Frazao, J. M. Baptista, and J. L. Santos, "Temperature-independent strain sensor based on a Hi-Bi photonic crystal fiber loop mirror," IEEE 
Sensors Journal, 2007, 7(10): 1453-1455.

[183] P. Zu, C. C. Chan, Y. Jin, T. Gong, Y. Zhang, L. H. Chen, et al., "A temperature-insensitive twist sensor by using low-birefringence photoniccrystal-fiber-based Sagnac interferometer," IEEE Photonics Technology Letters, 2011, 23(13): 920-922.

[184] H. Gong, C. C. Chan, L. Chen, and X. Dong, "Strain sensor realized by using low-birefringence photonic-crystal-fiber-based Sagnac loop," IEEE Photonics Technology Letters, 2010, 22(16): 1238-1240.

[185] H. P. Gong, C. C. Chan, P. Zu, L. H. Chen, and X. Y. Dong, "Curvature measurement by using low-birefringence photonic crystal fiber based Sagnac loop," Optics Communications, 2010, 283(16): 3142-3144.

[186] S. Pu, L. Luo, J. Tang, L. Mao, and X. Zeng, "Ultrasensitive refractive-index sensors based on tapered fiber coupler with Sagnac loop," IEEE Photonics Technology Letters, 2016, 28(10): 1073-1076.

[187] P. L. Swart, "Long-period grating Michelson refractometric sensor," Measurement Science and Technology, 2004, 15(8): 1576.

[188] D. Wu, T. Zhu, and M. Liu, "A high temperature sensor based on a peanut-shape structure Michelson interferometer," Optics Communications, 2012, 285(24): 5085-5088.

[189] L. Xu, L. Jiang, S. Wang, B. Li, and Y. Lu, "High-temperature sensor based on an abrupt-taper Michelson interferometer in single-mode fiber," Applied Optics, 2013, 52(10): 2038-2041.

[190] Z. Tian, S. S. H. Yam, and H. P. Loock, "Refractive index sensor based on an abrupt taper Michelson interferometer in a single-mode fiber," Optics Letters, 2008, 33(10): 1105-1107.

[191] L. M. N. Amaral, O. Frazão, J. L. Santos, and A. B. L. Ribeiro, "Fiber-optic inclinometer based on taper Michelson interferometer," IEEE Sensors Journal, 2011, 11(9): 1811-1814.

[192] N. Zhao, H. Fu, M. Shao, X. Yan, H. Li, Q. Liu, et al., "High temperature probe sensor with high sensitivity based on Michelson interferometer," Optics Communications, 2015, 343: 131-134.
[193] L. Duan et al., "Heterogeneous all-solid multicore fiber based multipath Michelson interferometer for high temperature sensing," Opt. Express, vol. 24, no. 18, p. 20210, 2016.

[194] L. Duan, P. Zhang, M. Tang, R. Wang, Z. Zhao, $\mathrm{S}$. Fu, et al., "Heterogeneous all-solid multicore fiber based multipath Michelson interferometer for high temperature sensing," Optics Express, 2016, 24(18): 20210-20218.

[195] K. Qi, Y. Zhang, J. Sun, and G. Yi, "All-fiber high temperature and refractive index sensor based on three microspheres array Michelson interferometer," Optics \& Laser Technology, 2020, 129: 106300.

[196] S. Zhang, L. Yin, Y. Zhao, A. Zhou, and L. Yuan, "Bending sensor with parallel fiber Michelson interferometers based on Vernier-like effect," Optics \& Laser Technology, 2019, 120: 105679.

[197] Y. Jin, C. C. Chan, Y. Zhang, X. Dong, and P. Zu, "Temperature sensor based on a pressure-induced birefringent single-mode fiber loop mirror," Measurement Science and Technology, 2010, 21(6): 065204.

[198] B. Dong, J. Hao, C. Y. Liaw, and Z. Xu, "Cladding-mode resonance in polarizationmaintaining photonic-crystal-fiber-based Sagnac interferometer and its application for fiber sensor," Journal of Lightwave Technology, 2011, 29(12): 1759-1763.

[199] G. Kim, K. Hwang, K. Lee, K. S. Lee, M. S. Youn, Y. G. Han, et al., "Strain and temperature sensitivities of an tapered hollow-core photonic bandgap fiber based on interferometer," OECC 2010 Technical Digest, 2010, 17(4): 644-645.

[200] H. M. Kim, T. H. Kim, B. Kim, and Y. Chung, "Temperature-insensitive torsion sensor with enhanced sensitivity by use of a highly birefringent photonic crystal fiber," IEEE Photonics Technology Letters, 2010, 22(20): 1539-1541.

[201] H. Y. Fu, H. Y. Tam, L. Y. Shao, X. Dong, P. K. A. Wai, C. Lu, et al., "Pressure sensor realized with polarization-maintaining photonic crystal fiber-based Sagnac interferometer," Applied Optics, 2008, 47(15): 2835-2839. 